\title{
Review \\ Factors Affecting Hydrogen Adsorption in Metal-Organic Frameworks: A Short Review
}

\author{
Vladimír Zeleňák 1,*(D) and Ivan Saldan 1,2 (D) \\ 1 Department of Inorganic Chemistry, Faculty of Science, Pavol Jozef Šafárik University in Košice, \\ Moyzesova 11, 04154 Košice, Slovakia; saldanivan@gmail.com \\ 2 Department of Physical and Colloid Chemistry, Faculty of Chemistry, Ivan Franko National University \\ of Lviv, Kyryla and Mefodia 6, 79005 Lviv, Ukraine \\ * Correspondence: vladimir.zelenak@upjs.sk
}

check for

updates

Citation: Zeleňák, V.; Saldan, I.

Factors Affecting Hydrogen

Adsorption in Metal-Organic

Frameworks: A Short Review.

Nanomaterials 2021, 11, 1638.

https://doi.org/10.3390/

nano11071638

Academic Editors: Ki-Hyun Kim,

Dimitrios Giannakoudakis,

Mariusz Barczak and Jorge Pasán

Received: 16 April 2021

Accepted: 18 June 2021

Published: 22 June 2021

Publisher's Note: MDPI stays neutral with regard to jurisdictional claims in published maps and institutional affiliations.

\begin{abstract}
Metal-organic frameworks (MOFs) have significant potential for hydrogen storage. The main benefit of MOFs is their reversible and high-rate hydrogen adsorption process, whereas their biggest disadvantage is related to their operation at very low temperatures. In this study, we describe selected examples of MOF structures studied for hydrogen adsorption and different factors affecting hydrogen adsorption in MOFs. Approaches to improving hydrogen uptake are reviewed, including surface area and pore volume, in addition to the value of isosteric enthalpy of hydrogen adsorption. Nanoconfinement of metal hydrides inside MOFs is proposed as a new approach to hydrogen storage. Conclusions regarding MOFs with incorporated metal nanoparticles, which may be used as nanoscaffolds and/or $\mathrm{H}_{2}$ sorbents, are summarized as prospects for the near future.
\end{abstract}

Keywords: adsorption; hydrogen; MOF; nanoconfinement; metal hydrides

\section{Introduction}

Creating an environmentally friendly and carbon-neutral society is currently a significant challenge. An emphasis on reducing the carbon footprint of human activities and efforts made to adopt sustainable and renewable energy sources resonate at various levels of society. Supported by funding of approximately EUR 1 billion, the European Commission has requested research and innovation projects aimed at responding to the climate crisis, and to help protect Europe's unique ecosystems and biodiversity [1,2]. Numerous areas and activities exist in which society, politicians, researchers, and engineers are focusing on building a natural and more environmentally friendly economy. The transport sector and the automotive industry represent significant challenges. The introduction and use of batteries and electric vehicles is an important step toward reducing the carbon footprint of traffic; however, this strategy is applicable to urban transport rather than to freight, air, or shipping. Several large ocean-sailing container ships produce more harmful emissions than all the cars in the world combined. A solution to reduce greenhouse gases in various human activities, including heavy transport, is offered by hydrogen technologies, which have advanced considerably in recent years. Several economic forecasts indicate the approaching period of a hydrogen-based economy [3,4]. An example of this trend may be seen in the Olympic Games in Tokyo 2021 [5,6], where the Olympic torch is going to be powered by hydrogen, and Japan wants to use the Olympic games to promote hydrogen to the world [5,6]. Another sign of this trend is the anticipated growth of hydrogen technology companies' share prices on the world's stock exchanges [7].

The development of hydrogen technologies and a wider use of hydrogen fuel cell systems require new materials that can store large amounts of hydrogen at relatively low pressures with small volume, low weight, and fast kinetics for recharging. An ultimate system objective in 2020 for automobile fueling was set by the U.S. Department of Energy (DoE) at $\sim 7 \mathrm{wt} \%$ hydrogen by weight [8]. Various materials have been studied in this 
respect, e.g., metal hydride systems [9-18]; however, numerous problems are associated with the use of high-temperature $\mathrm{H}_{2}$ storage materials (interstitial and complex metal hydrides or their reactive hydride composites), namely, their high cost, low specific uptake by weight, unfavorable kinetics requiring heating cycles, and susceptibility to contamination by impurities. In addition, various carbon-based adsorbents (carbon black, intercalated graphite, carbon nanotubes, and nanoporous polymer networks) have been widely studied and categorized as low temperature $\mathrm{H}_{2}$ storage materials, although they have been subject to ambiguous results [19-27]. It remains difficult to systematically engineer the molecular structure of these hydrogen adsorbers and identify specific hydrogen binding sites.

Among the most challenging materials for hydrogen storage are porous coordination polymers, also called metal-organic frameworks (MOFs). MOFs are two- or threedimensional porous crystalline materials with infinite lattices. As a result of their ultra-high surface area values (more than $2500 \mathrm{~m}^{2} \cdot \mathrm{g}^{-1}$ measured by the Brunauer-Emmett-Teller (BET) approach), they were found to be promising gas adsorbers for small gaseous molecules, including $\mathrm{CH}_{4}, \mathrm{CHCl}_{3}, \mathrm{CCl}_{4}, \mathrm{C}_{6} \mathrm{H}_{6}, \mathrm{C}_{6} \mathrm{H}_{12}, \mathrm{CO}_{2}, \mathrm{Ar}, \mathrm{N}_{2}$, and $\mathrm{H}_{2}$. The main benefit of MOFs is their reversible and high-rate hydrogen adsorption process. A reasonable number of $\mathrm{H}_{2}$ molecules inside the body of MOFs may only be obtained at very low temperatures [28-54]. To date, MOFs have shown significant progress in applications of gas separation, catalysis, and coordination chemistry. For example, homochiral MOFs have become one of the most widely studied porous materials to enable enantioseparation [55]. Properties of zeolites and MOFs have been combined in metal-organic zeolites (MOZs) and proposed as promising catalysts [56]. The Cu-based boron imidazolate cage (BIF-29) with six exposed mononuclear $\mathrm{Cu}$ centers [57] and Ti-based MOFs (FIR-125, FIR-125, and FIR-127) made of $\mathrm{Ti}_{8} \mathrm{O}_{8}\left(\mathrm{CO}_{2}\right)_{16}$ building units [58] have been considered to be effective photocatalytic materials.

In the present review, we summarize the known physical and chemical factors affecting hydrogen adsorption in porous MOFs. We also propose new views. Thousands of different MOF structures are currently known, therefore, to clearly discuss the influence of the relevant factors of hydrogen adsorption, we focus mainly on MOFs that have cubic cavities of uniform size and internal structure. The focus is on the MOF- 5 and its isorecticular MOF series (IRMOFs), that have the same framework topology and surface environment, but different pore sizes. When appropriate, we also discuss the known MOFs of other symmetries. Additionally, we provide a perspective of new MOF-based materials for effective hydrogen sorption.

\section{Basic Knowledge of Interaction between Solid Porous MOFs and Gaseous Hydrogen}

\subsection{Hydrogen Sorption}

Gas sorption and desorption (where the latter is the reverse of sorption) of the sorbate (e.g., gaseous hydrogen) by the sorbent (e.g., MOFs) is a dynamic process. Absorption occurs when the adsorbate may be incorporated into the internal structure of the adsorbent; hence, the structure and properties of the absorbate and absorbent may be modified. Absorption is often related to chemisorption, which occurs when the interaction force between the sorbent surface and the adsorbate is similar to that of chemical bonding in bulk compounds. Adsorption is a physical process of attracting atoms, ions, or molecules of the sorbate to the sorbent surface or interfacial layer and is related to weak intermolecular forces (van der Waals forces) of the same kind as those responsible for the nonideality of gases and the condensation of vapors. It is assumed that the electronic structures of sorbate and sorbent are not affected by physical adsorption. In the case of molecular $\mathrm{H}_{2}$ physisorption, the $\mathrm{H}-\mathrm{H}$ bond in the gas phase is preserved in the sorbed state, whereas in the case of $\mathrm{H}_{2}$ chemisorption, the $\mathrm{H}-\mathrm{H}$ bond is broken during the sorption process. Therefore, chemisorption can only occur in a monolayer on the sorbent surface, whereas physisorption is usually accompanied by multilayer adsorption. The heat values of hydrogen adsorption for most nanoporous materials, including MOFs, crosslinked polymers, or porous carbons, are within the range of $4-7 \mathrm{~kJ} \cdot \mathrm{mol}^{-1}[24]$. 


\subsection{Surface Area}

According to IUPAC [59], porous materials are classified according to their pore sizes: macroporous (pore size $>500 \AA$ ), mesoporous (pore size $\sim 20-500 \AA$ ), and microporous (pore size $<20 \AA$ ) materials. The microporous materials may be classified into supermicroporous (pore size $\sim 7-20 \AA$ ) and ultramicroporous (pore size $<7 \AA$ ). Most MOFs are microporous materials, although supermicroporous and ultramicroporous MOFs are well known. Ultramicropores are filled at very low relative pressures $p / p_{o}$ (where $p$ is the equilibrium pressure and $p_{o}$ is the saturation vapor pressure at the adsorption temperature) directed by gas-solid interactions, and the rates of adsorption highly depend on temperature. In supermicropores, in addition to gas-solid interactions, a cooperation effect (when pore filling occurs at a relatively low $p / p_{o}$ value) takes place. Pore filling occurs when it is energetically as favorable for a gas molecule to exist between the monolayers of the gas in the center of the pore as it is to complete the monolayer coverage. A continuous monolayer of adsorbate molecules surrounding uniform sorbent surfaces is the main concept of the Langmuir adsorption model:

$$
\Theta_{A}=\frac{K_{e q}^{A} p_{A}}{1+K_{e q}^{A} p_{A}}
$$

where $\theta_{A}$ is the fractional occupancy of adsorption sites; $p_{A}$ is the partial pressure of the adsorbate; $K_{e q}^{A}$ is the equilibrium constant of the chemical interaction between the adsorbate molecule and the empty site. Most MOFs have different types of atomic surfaces; therefore, the interactions with gases highly depend on the metal atoms and organic ligands forming MOFs. At the evaluation of the MOF surface area, a common Langmuir equation may not be suitable. This is mainly due to localized adsorptions in ultramicropores and multilayer adsorption in supermicropores of MOFs.

The BET theory considers multilayer adsorption; therefore, this approach has become a common and simple method to calculate the surface area:

$$
\frac{p / p_{0}}{n\left(1-p / p_{0}\right)}=\frac{1}{n_{m} C}+\frac{(C-1)\left(p / p_{0}\right)}{n_{m} C}
$$

where $n$ is the specific amount of the adsorbed gas at the relative pressure of $p / p_{0}, C$ is the BET constant, and $n_{m}$ is the specific monolayer capacity. It has been shown that the BET surface area calculated from the $\mathrm{N}_{2}$ adsorption isotherm obtained by the Grand Canonical Monte Carlo (GCMC) simulation is very similar to the experimental BET surface area [60]. Reasonable values of the BET surface areas; however, may only be obtained in a linear range of Equation (2). In addition, this condition was experimentally confirmed mainly using $p / p_{o}$ values of $0.05-0.3$, which are only applicable to non-porous or mesoporous materials. In the case of supermicroporous MOFs and ultramicroporous materials with pores that vary in terms of size, form, and chemical surroundings, the BET calculation on the surface area is inaccurate. In 2007, Llewellyn et al. recommended consistent criteria to address this issue [61]: (1) the BET approach should be limited to the range in which the term $n\left(1-p / p_{o}\right)$ increases continuously with the $p / p_{o}$ value; (2) the $C$ constant resulting from the linear fit should be positive with a value of at least 10; and (3) the $n_{m}$ value corresponds to a certain value of $p / p_{0}$, which must be located within the linear region chosen for the area calculation. I. Senkovska and S. Kaskel [62] concluded that strong surface tension effects during subcritical adsorption can cause deformation of adsorbent structure, especially in the case of MOFs in which the tension forces act simultaneously when the pore is being filled. As a result, that the calculated surface area of the framework depends on the pressure range used in the calculation, the BET equation to determine the surface area of MOFs should be adapted to a specific situation. The specific surface areas of MOFs are generally determined from the $\mathrm{N}_{2}$ adsorption isotherms at $77 \mathrm{~K}$; however, it should be mentioned that the use of alternative probe molecules will often result in different values of surface area. 
In monolayer adsorption, all adsorbed $\mathrm{H}_{2}$ molecules are in contact with the sorbent surface. The monolayer can be in the form of different surface structures, including a close-packed array. The monolayer hydrogen capacity $\left(n_{a, m}\right)$ is determined as the number of $\mathrm{H}_{2}$ molecules sufficient to completely cover the sorbent surface. The surface coverage $(\theta)$ is assigned as the ratio of the adsorbed amount of $\mathrm{H}_{2}$ to the monolayer hydrogen capacity. The surface area $\left(A_{s}\right)$ of the sorbent is usually calculated from the monolayer hydrogen capacity when the area effectively occupied by the $\mathrm{H}_{2}$ molecules in the complete monolayer $\left(\sigma_{m}\right)$ is known:

$$
A_{s}=n_{a, m} L \sigma_{m}
$$

where $L$ is Avogadro's constant. The specific surface area $\left(a_{s}\right)$ can be calculated as the ratio of $A_{s}$ to the mass $(m)$ of the sorbent:

$$
a_{s}=\frac{A_{s}}{m}
$$

\subsection{Surface Excess and the Total Adsorbed Amount of Hydrogen}

The adsorption process initially appears to be a simple procedure because, during the interaction between MOFs and the hydrogen gas, only the adsorption space exists (e.g., the adsorbed layer). In practice, however, to evaluate the total amount adsorbed $\left(n_{a}\right)$, the volume of the adsorption space $\left(V_{a}\right)$ is needed, which cannot be measured simply [60]. According to the Gibbs model, the difference in the amounts of the molecular hydrogen gas that would be present in the equivalent volume of the adsorbed phase in the presence and the absence of adsorption is a quantity called the surface excess amount $n_{\sigma}$. In this case, adsorption is assumed to be two-dimensional (i.e., $V_{a}=0$ ) and to occur on the Gibbs dividing surface (GDS), which restricts the volume available for the homogeneous gas phase $\left(V_{g}\right)$. Calculating the gas phase amount $\left(n_{g}\right)$ in equilibrium with the adsorbent may be carried out with the appropriate gas laws. In practice, the $n_{\sigma}$ value may be determined by adsorption manometry or gravimetry. In the case of of $\mathrm{H}_{2}$ gas adsorption up to 1 bar, the $n_{a}$ and $n_{\sigma}$ values are nearly identical, provided the latter is calculated with the GDS very close to the adsorbent surface. When the $\mathrm{H}_{2}$ pressure $>1$ bar, the difference between the value of $n_{a}$ and $n_{\sigma}$ is clear. The experimental $n_{\sigma}$ data can be converted into the corresponding $n_{a}$ value, when the volume of the solid MOF $\left(V_{s}\right)$ and $V_{a}$ and are known. When the GDS exactly coincides with the actual adsorbent surface [63], the total adsorbed amount of hydrogen in the MOF is:

$$
n_{a}=n_{\sigma}+C_{g} V_{a}
$$

where $n_{a}$ and $n_{\sigma}$ values are in $\mathrm{mg} \cdot \mathrm{g}^{-1} ; C_{g}$ is the compressed gas concentration at a given temperature and pressure, in $\mathrm{g} \cdot \mathrm{cm}^{-3}$; and $V_{a}$ is the volume of the adsorption space in $\mathrm{cm}^{3}$. The $n_{a}$ value can be derived from the excess adsorption isotherm, which is the relationship between the $n_{\sigma}$ value and the equilibrium pressure of the gas $(p)$ at constant temperature. At gas adsorption temperatures below the critical point, the $p / p_{o}$ value is usually considered, whereas at those above the critical point, only the $p$ value must be considered, because no saturation vapor pressure $\left(p_{0}\right)$ exists.

The authors of [64] considered the volume of a pore as a complex object with a volume of the free-gas phase between two volumes of adsorbed molecules $\left(V_{a}\right)$. In a simplified case, the $V_{a}$ value is taken as a pore volume and may be calculated using the crystallographic density of the sample $\left(d_{\text {bulk }}\right)$ and the skeletal density of the material $\left(d_{\text {skeletal }}\right)$ [40]:

$$
V_{a}=\frac{1}{d_{\text {bulk }}}-\frac{1}{d_{\text {skeletal }}}
$$

The obtained $V_{a}$ value is measured in $\mathrm{cm}^{3} \cdot \mathrm{g}^{-1}$ and $d_{\text {skeletal }}$ is measured in $\mathrm{g} \cdot \mathrm{cm}^{-3}$ :

$$
d_{\text {skeletal }}=\frac{m}{V_{\text {skeletal }}}
$$


where $m$ is the sample mass in grams and $V_{\text {skeletal }}$ is the skeletal volume of MOFs in $\mathrm{cm}^{3}$. $V_{\text {skeletal }}$ is normally determined using the gas sorption isotherm measured at $298 \mathrm{~K}$ up to the pressure of 100 bar. The hydrogen adsorption capacity in MOFs is expressed in $\mathrm{wt}^{\mathrm{O}} \%$ but more often the mass in $\mathrm{mg}$ or $\mathrm{mmol}$ of $\mathrm{H}_{2}$ adsorbed per gram of MOF is used [65].

\subsection{Isosteric Enthalpy of Hydrogen Adsorption}

Using the differential energies/enthalpies of adsorption $\left(\Delta_{a d s} U\right) /\left(\Delta_{a d s} H\right)$ versus the adsorbed total amount $\left(n_{a}\right)$, the energetics of micropore filling can be estimated. The $\Delta a_{d s} H$ value at constant coverage can be evaluated by determining the isotherms at two or more different $T$ values. The respective data processing may be related graphically as $\ln P$ for a given $n_{a}$ value as a function of $1 / T$. Using the Clausius-Clapeyron equation, it is possible to establish the "isometric heat of adsorption" when it is assumed that there is no enthalpy or entropy variation with $T$ [66]:

$$
\Delta_{a d s} H_{n a}=R\left(\frac{\partial \ln [P]}{\partial \frac{1}{T}}\right)_{n_{a}}
$$

where $\Delta_{a d s} H_{n a}$ is the enthalpy of differential adsorption and $R$ is the gas constant. By comparison, using adsorption isotherms obtained at different temperatures, the energetics data assessment leads to the isosteric heat of hydrogen adsorption $\left(Q_{s t}\right)$. As a result, that $Q_{s t}$ is equal to $-\Delta_{a d s} H$, the term "isosteric enthalpy of adsorption" is preferable [55]. Therefore, energy of hydrogen physisorption can be obtained directly from the hydrogen adsorption calorimetry (which is more reliable) or indirectly using the Clausius-Clapeyron relation:

$$
Q_{s t}=R \ln \left(\frac{P_{1}}{P_{2}}\right) \frac{T_{1} T_{2}}{T_{2}-T_{1}}
$$

The accuracy of this type of calculation depends on the measurement of the $P$ values, which depends on the "adsorbent-adsorbate balance". Typical problems appear in the case of gas adsorption in microporous materials at low $P$ values. A small deviation in equilibrium due to molecular diffusion or thermal transfer can generate a relatively large variation in pressure measurements, leading to dispersion of the $Q_{s t}$ value [66]. Evaluation of the $Q_{s t}$ value has also been proposed using the Chakraborty-Saha-Koyama model [67] based on the concepts of chemical equilibrium potentials between the gaseous and adsorbed phases, the state equation, and the Maxwell relationships. The conventional form of $Q_{s t}$ with the Clausius-Clapeyron approach was obtained as:

$$
Q_{\text {st (conventional })}=R T^{2}\left[\left(\frac{\partial \ln [P]}{\partial T}\right)_{m_{a}}\right]
$$

where $m_{a}$ is the adsorbate mass.

\section{Structure and Topology of MOFs Studied for Hydrogen Adsorption}

\subsection{MOF-5 and Isorecticular Compounds}

The group of Yaghi described the first carboxylate-based MOFs, such as MOF-2 [68] and MOF-5 [69], in the mid-1990s. Subsequently, significant research interest has been shown in these materials, which have been tested for applications such as gas storage, separation, and conversion [70,71], and drug delivery [72]. As a result, several novel MOF crystal structures have been described, and thousands of different examples with various symmetries and topologies are known [68-72].

Due to the large number of existing MOFs and their structural diversity, in this work we focus mainly on MOFs with cubic symmetry, including the IRMOF series. 
The well-known MOF-5 (also called IRMOF-1) was prepared under solvothermal conditions using the $\mathrm{Zn}^{2+}$ cation and 1.4-benzenedicarboxylic acid $\left(\mathrm{H}_{2} \mathrm{BDC}\right)$ :

$$
4 \mathrm{Zn}^{2+}+3 \mathrm{H}_{2}\left[\mathrm{O}_{2} \mathrm{C}-\mathrm{C}_{6} \mathrm{H}_{4}-\mathrm{CO}_{2}\right]+8 \mathrm{OH}^{-} \rightarrow 3 \mathrm{Zn}_{4} \mathrm{O}\left[\mathrm{O}_{2} \mathrm{C}-\mathrm{C}_{6} \mathrm{H}_{4}-\mathrm{CO}_{2}\right]_{3}+7 \mathrm{H}_{2} \mathrm{O}
$$

This compound crystallizes in the $F m-3 m$ space group with a cubic symmetry and composition of $\left[\mathrm{Zn}_{4} \mathrm{O}(\mathrm{BDC})_{3}\right]_{\mathrm{n}}$. The structure is formed by four $\mathrm{Zn}^{2+}$ cations that share one oxygen atom, forming regular tetrahedral $\left[\mathrm{Zn}_{4} \mathrm{O}\right]^{6+}$ clusters [73]. Each zinc atom is further tetrahedrally coordinated and each edge of the $\mathrm{Zn}$ tetrahedron is capped by a [BDC-CO $\left.\mathrm{CO}_{2}\right]$ group to form a $\left[\mathrm{Zn}_{4}(\mathrm{O})\left(\mathrm{CO}_{2}\right)_{6}\right]$ cluster [73]. These clusters are subsequently bridged by six BDC molecules in octahedral coordination to form a robust microporous cubic structure (Figure 1). Figure 1 shows one cavity of MOF-5-the overall structure is more complex, composed of larger cavities (15.1 $\AA$ in diameter) and smaller cavities (11.0 in diameter) in an alternating manner, so that the unit cell consists of four larger and four smaller cavities [69]. The calculated surface area of MOF-5 is about $2500-3000 \mathrm{~m}^{2} \cdot \mathrm{g}^{-1}$.

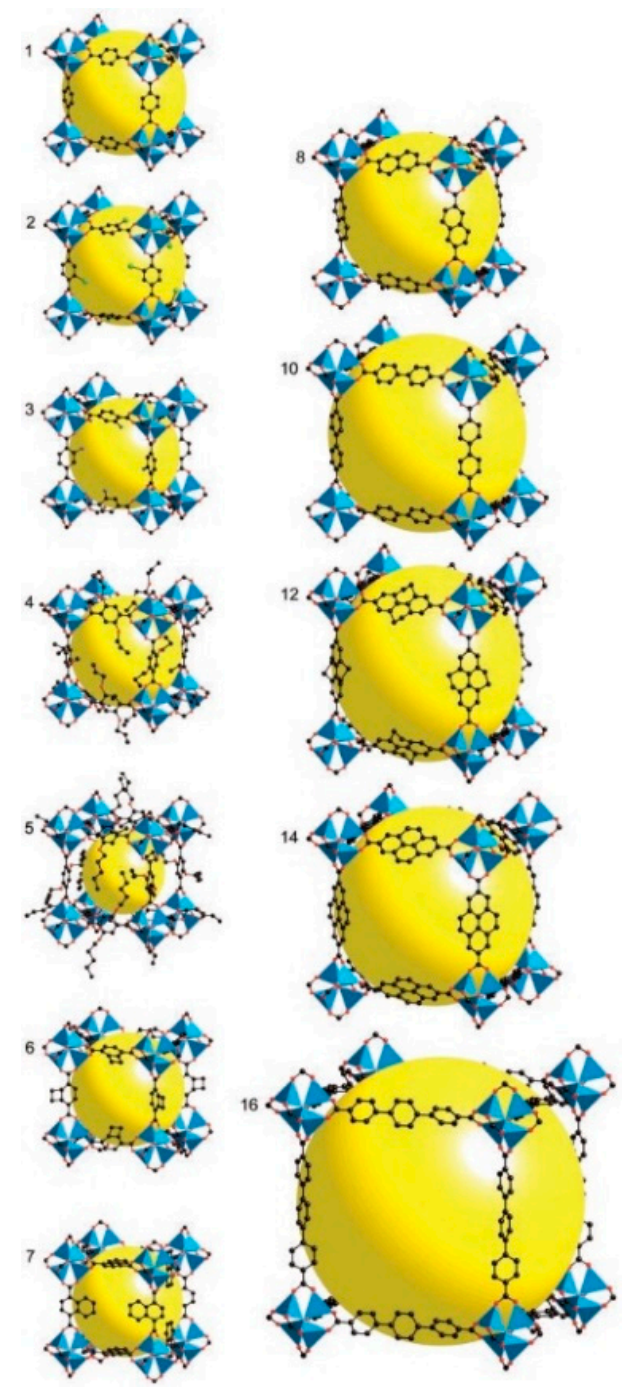

Figure 1. Isoreticular series of MOF-5 (IRMOF-1). Crystal structures of the IRMOFs-n ( $n=1,7,8$, $10,12,14$, and 16), labeled respectively. The color scheme is as follows: $\mathrm{Zn}$ (blue polyhedra), $\mathrm{O}$ (red spheres), C (black spheres), Br (green spheres in 2), amino-groups (blue spheres in 3). The large yellow spheres represent the largest van der Waals spheres that would fit in the cavities without touching the frameworks. Reprinted with permission from [73]. Copyright (C 2002, American Association for the Advancement of Science. All rights reserved. 
The crystal structure of MOF-5 can also be described using topology tools. The structure can be viewed as a simple cubic six-connected net with two simplifications: (1) the nodes (vertices) of the net are replaced by clusters of the secondary building units (SBUs), which are $\mathrm{Zn}_{4} \mathrm{O}$; and (2) the edges of the net are replaced by infinite rods (struts) of [$\mathrm{O}_{2} \mathrm{C}-\mathrm{C}_{6} \mathrm{H}_{4}-\mathrm{CO}_{2}^{-}$] anions. MOF-5 is a prototype for a class of porous materials with similar structure constructed from octahedral [ $\mathrm{Zn}-\mathrm{O}-\mathrm{C}]$ clusters made of organo-dicarboxylate linkers (struts), where "organo" represents, for example, biphenyl, tetrahydropyrene, pyrene, or terphenyl. Depending on the size of the acid molecule used, holes of different sizes can be prepared. These isostructural compounds are referred to as IRMOFs and have the same framework topology. Pore size in IRMOFs can be incrementally varied from 3.8 to $28.8 \AA$, and the open space can represent up to $91.1 \%$ of the crystal volume [73]. IRMOFs can be prepared with an organic linker substituted by $-\mathrm{Br},-\mathrm{NH}_{2},-\mathrm{OC}_{3} \mathrm{H}_{7},-\mathrm{OC}_{5} \mathrm{H}_{11},-\mathrm{C}_{2} \mathrm{H}_{4}$, or $-\mathrm{C}_{4} \mathrm{H}_{4}$. From the IRMOF series, IRMOF-20, which is formed by thieno[3, 2-b]thiophene-2,5dicarboxylate fragments, is of particular interest from a hydrogen adsorption perspective because, above 1 bar, IRMOF-20 shows higher gravimetric and volumetric hydrogen density than MOF-5, as shown by an isothermal pressure swing experiment between $\mathrm{P}_{\min }=5$ bar and $\mathrm{P}_{\max }=35,50$, or 100 bar [74].

\subsection{Other MOFs Formed by Metal Clusters Interconnected by Carboxylate Linkers}

Another type of MOF that may be promising for hydrogen adsorption is represented by a framework with a cubic structure based on metal clusters interconnected by polytopic carboxylate linkers. The well-known representatives of this MOF family are UiO (where UiO refers to the University of Oslo) and HKUST-1 (HKUST referring to the Hong Kong University of Science and Technology). UiO-66 is prepared from $\mathrm{Zr}^{2+}$ ions and [BDC] ${ }^{2-}$ ligands and crystalized in a cubic lattice with the Fm-3m space group, similar to MOF-5, and the SBU composition of $\left[\mathrm{Zr}_{6} \mathrm{O}_{4}(\mathrm{OH})_{4}(\mathrm{COO})_{12}\right]$ (Figure $\left.2 \mathrm{a}\right)[75,76]$.
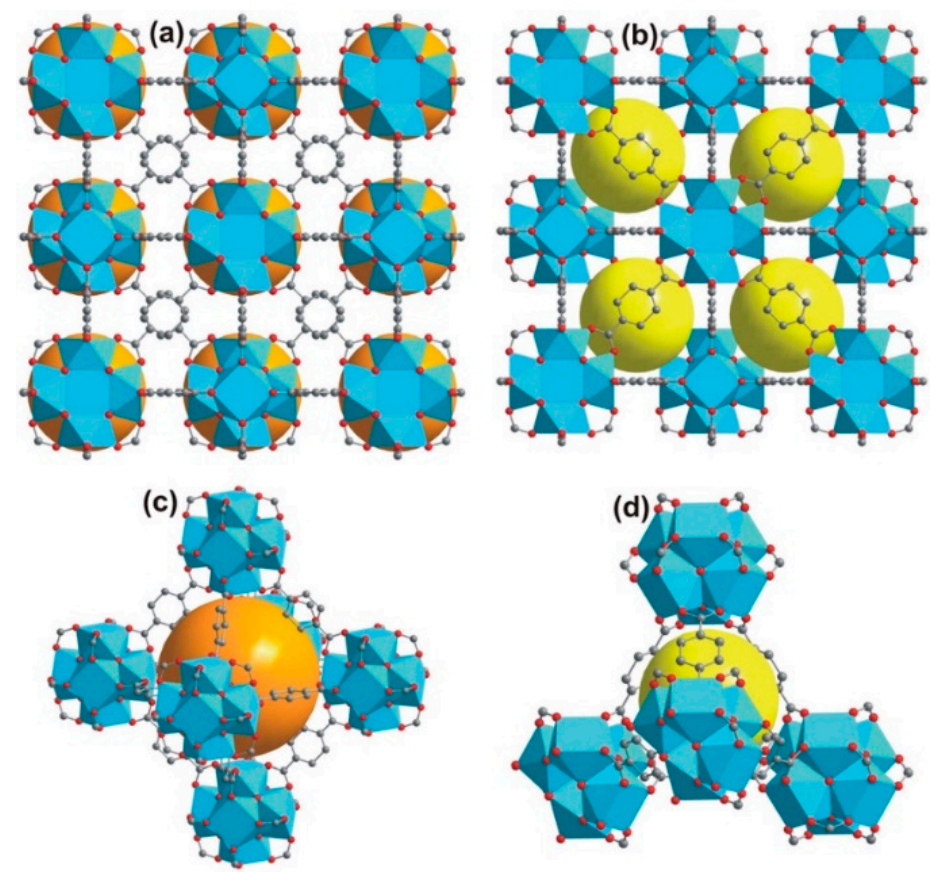

Figure 2. Ball-and-stick representations of the 3D cubic framework structure of UiO-66 (a,b). Parts of the framework showing spatial arrangements of the octahedral and the tetrahedral cages are represented by orange and yellow spheres, respectively $(\mathbf{c}, \mathbf{d})$. Magnified views of the octahedral and tetrahedral cages of $\mathrm{Zr}$ atoms are displayed as $\mathrm{Zr}$ (blue polyhedral), $\mathrm{O}$ (red spheres), and C (gray spheres). The hydrogen atoms and guest molecules have been removed from all the structural plots for clarity. Reprinted with permission from [76]. Copyright (C) 2013, Royal Society of Chemistry. All rights reserved. 
The crystal structure of UiO-66 has two types of the cavities [76]: (1) an octahedral cavity with a size of $\sim 9 \AA$ (orange spheres in Figure 2a,c), and (2) a tetrahedral cavity with a size of $\sim 7 \AA$ (yellow spheres in Figure $2 b, d$ ). The UiO-66 material is unique because of its hydrothermal, mechanical, and thermal stability. The surface area value of UiO-66 is $1187 \mathrm{~m}^{2} \cdot \mathrm{g}^{-1}$. By changing the [BDC] linker to a larger dicarboxylate ligand, an isorecticular $\mathrm{UiO}$ (Figure 3) can be prepared (e.g., UiO-67 [77], with surface area values within the range of 3000-4170 $\mathrm{m}^{2} \cdot \mathrm{g}^{-1}$ ). In addition, other isorecticular MOFs derived from zirconium $\mathrm{Zr}_{6}$ clusters, present in UiO-66, have been synthesized (e.g., NU-1101, MOF-808, and PCN-521).

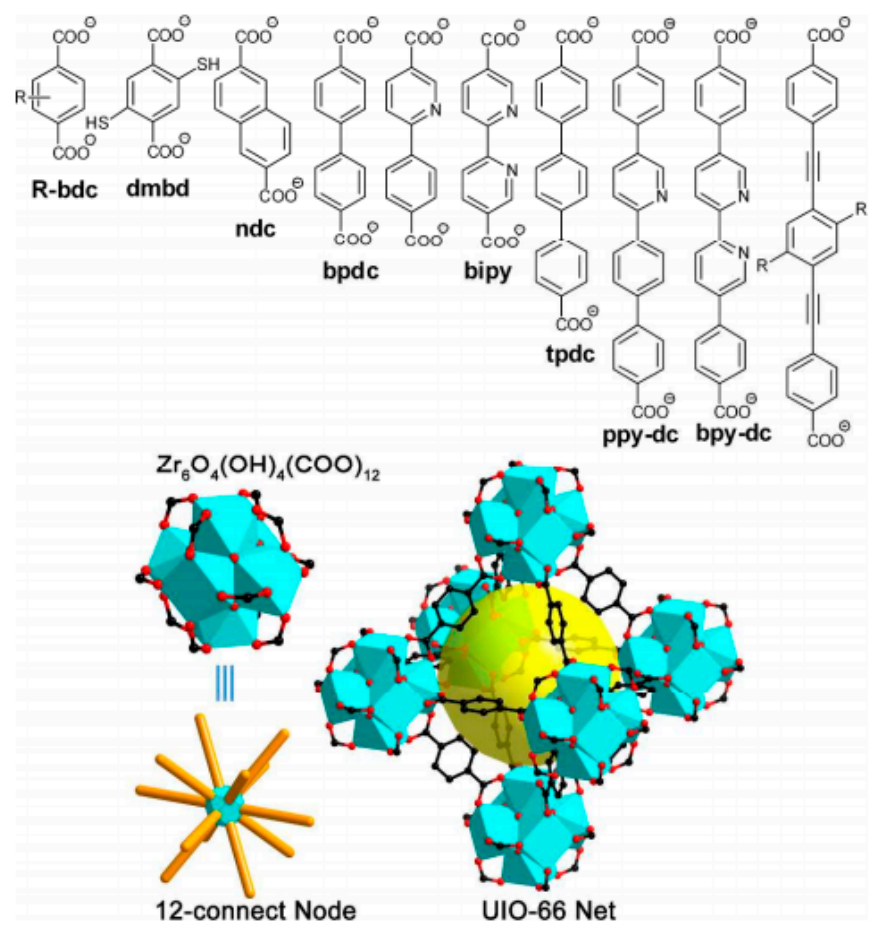

Figure 3. Representative ditopic carboxylate linkers used in the synthesis of the UiO frameworks. SBU with chemical composition of $\left[\mathrm{Zr}_{6} \mathrm{O}_{4}(\mathrm{OH})_{4}(\mathrm{COO})_{12}\right]$ and the UiO-66 octahedral cage. The color scheme is as follows: $\mathrm{Zr}$ (blue polyhedra), $\mathrm{O}$ (red spheres), $\mathrm{C}$ (black spheres). The yellow sphere represent the largest van der Waals spheres that would fit in the cavity without touching the frameworks. Reprinted with permission from [77]. Copyright (C) 2014, Royal Society of Chemistry. All rights reserved.

The crystal structure of HKUST- 1 with the composition of $\left\{\left[\mathrm{Cu}_{3}(\mathrm{BTC})_{2}\left(\mathrm{H}_{2} \mathrm{O}\right)_{3}\right]\right\}_{\mathrm{n}}$ was first studied in 1999 [78]. It is composed of $\mathrm{BTC}^{3-}$ linkers $\left(\mathrm{H}_{3} \mathrm{BTC}=1,3,5\right.$-benzenetricarboxylic acid), which coordinate with $\mathrm{Cu}^{2+}$ ions to form a cubic lattice with the $\mathrm{Fm}-3 m$ space group. Within HKUST-1, the $\mathrm{Cu}^{2+}$ ions are organized in dimers with a "paddle wheel" cluster, in which each copper atom is coordinated by four oxygen atoms from the [BTC $\left.{ }^{3-}\right]$ bridging ligands. The fifth coordination site on each $\mathrm{Cu}^{2+}$ ion is occupied by an oxygen atom from a water molecule, which can be easily removed by activation. Coordination of [BTC ${ }^{3-}$ ] with the $\mathrm{Cu}^{2+}$ ions leads to the formation of a three-dimensional neutral skeleton with a surface area of $1500 \mathrm{~m}^{2} \cdot \mathrm{g}^{-1}$ and a complex structure [79] with three types of pores (see Figure 4).

It should be noted that, in addition to the structure types described above, there are also other well-known MOF structures, such as the MIL and DUT families. A detailed structural description of these MOFs exceeds the scope of this review, and in the structure description we focus mainly on the structures with a cubic symmetry. In addition, we describe the structures of two other MOFs, namely, PCN-610/NU-100 and NU-1501, because these MOFs show significant hydrogen adsorption capacities. Ahmed et al. [48] undertook a systematic assessment of published databases of real and hypothetical MOFs, and screened nearly half a million metal-organic frameworks, which were examined 
computationally. The most promising materials identified computationally were subsequently synthesized and characterized experimentally. Importantly, three MOFs with usable capacities surpassing that of IRMOF-20 were demonstrated: SNU-70, UMCM-9, and PCN-610/NU-100, of which the latter showed the highest storage capacities.

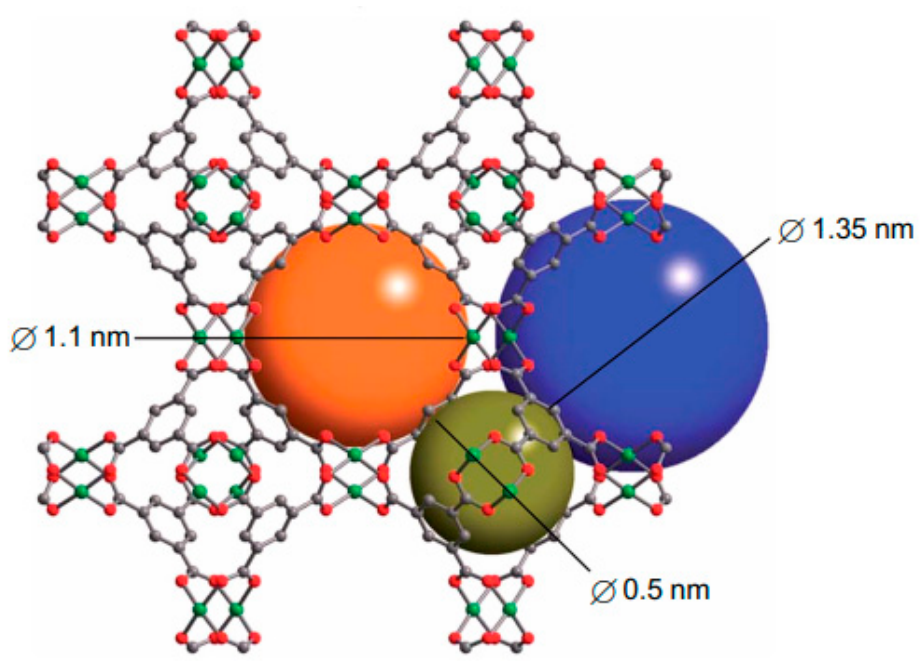

Figure 4. Crystal structure of HKUST-1 with three types of pores designated by differently colored spheres. Reprinted with permission from [79]. Copyright () The Royal Society of Chemistry 2014. All rights reserved.

Compound PCN-610/NU-100 contains ligands with $C_{3}$ symmetry, namely 5,50,500(((benzene-1,3,5-triyltris(ethyne-2,1-diyl))tris(benzene-4,1-diyl))tris-(ethyne-2,1-diyl))triisophthalic acid $\left(\mathrm{H}_{6}\right.$ ttei), with three coplanar isophthalate moieties. A solvothermal reaction of $\mathrm{H}_{6}$ ttei and copper(II) nitrate in DMF/ $\mathrm{HBF}_{4}$ yielded $\mathrm{Cu}_{3}\left(\mathrm{H}_{2} \mathrm{O}\right)_{3}(\mathrm{ttei}) \cdot 19 \mathrm{H}_{2} \mathrm{O} \cdot 22 \mathrm{DMF}$, whose Xray crystal structure revealed cubic $\mathrm{Fm}$-3m symmetry with a noninterpenetrating $(3,24)$ connected framework formed from $\mathrm{Cu}_{2}$-paddle-wheel units (see symbol "A" in Figure 5). Interconnection of these paddle wheel $\mathrm{Cu}_{2}(-\mathrm{COO})_{4}$ units with the $\mathrm{H}_{6}$ ttei ligand results in formation of three types of voids (see symbols " $\mathrm{B}$ ", "C", and " $\mathrm{D}$ " in Figure 5) with sizes $26.0,18.6$, and $12.0 \AA$, respectively. These voids can be described as cuboctahedra, truncated tetrahedra, and truncated octahedra [48].

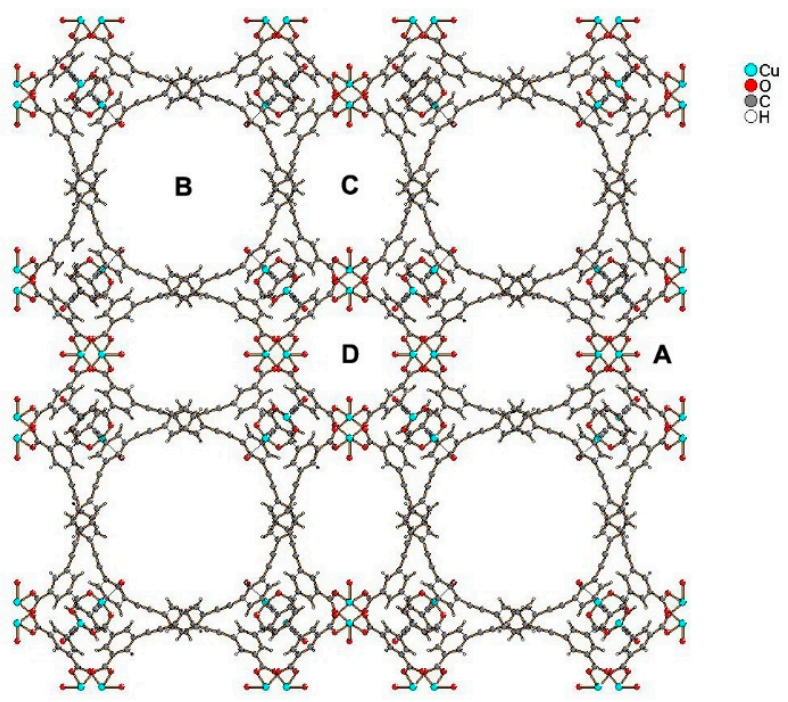

Figure 5. View of the structure of PCN-610/NU-100, where " $\mathrm{A}$ " shows paddle wheel $\mathrm{Cu}_{2}(-\mathrm{COO})_{4}$ units, and " $\mathrm{B}$ ", " $\mathrm{C}$ ", and " $\mathrm{D}$ " show three types of voids of different sizes present in the structure. 
Ultraporous MOFs, namely NU-1501-M (M = $\mathrm{Al}$ or Fe), based on metal trinuclear clusters, have been reported [80]. The high porosity and surface area of these MOFs yielded impressive gravimetric and volumetric storage performances for hydrogen and methane. In contrast to the compounds described above, the structure of these MOFs has hexagonal rather than cubic symmetry, and the space group $P \overline{6} m 2$. The compound is founded on the prismatic triptycene-based organic ligand, peripherally extended triptycene $\left(\mathrm{H}_{6} \mathrm{PET}-2\right)$, see Figure 6. The combination of these rigid trigonal prismatic linkers and $\mathrm{M}_{3} \mathrm{O}$ metal trimers $\left(\mathrm{M}=\mathrm{Al}^{3+}, \mathrm{Fe}^{3+}\right)$ forms MOFs with the formula $\left[\mathrm{Al}_{3}\left(\mathrm{~m}_{3}-\mathrm{O}\right)\left(\mathrm{H}_{2} \mathrm{O}\right)_{2}(\mathrm{OH})(\mathrm{PET}-2)\right]$ [80]. The compound exhibits 6-c acs topology, and have one type of open hexagonal channel with a pore size of $\sim 2.2 \mathrm{~nm}$ (see Figure 6).

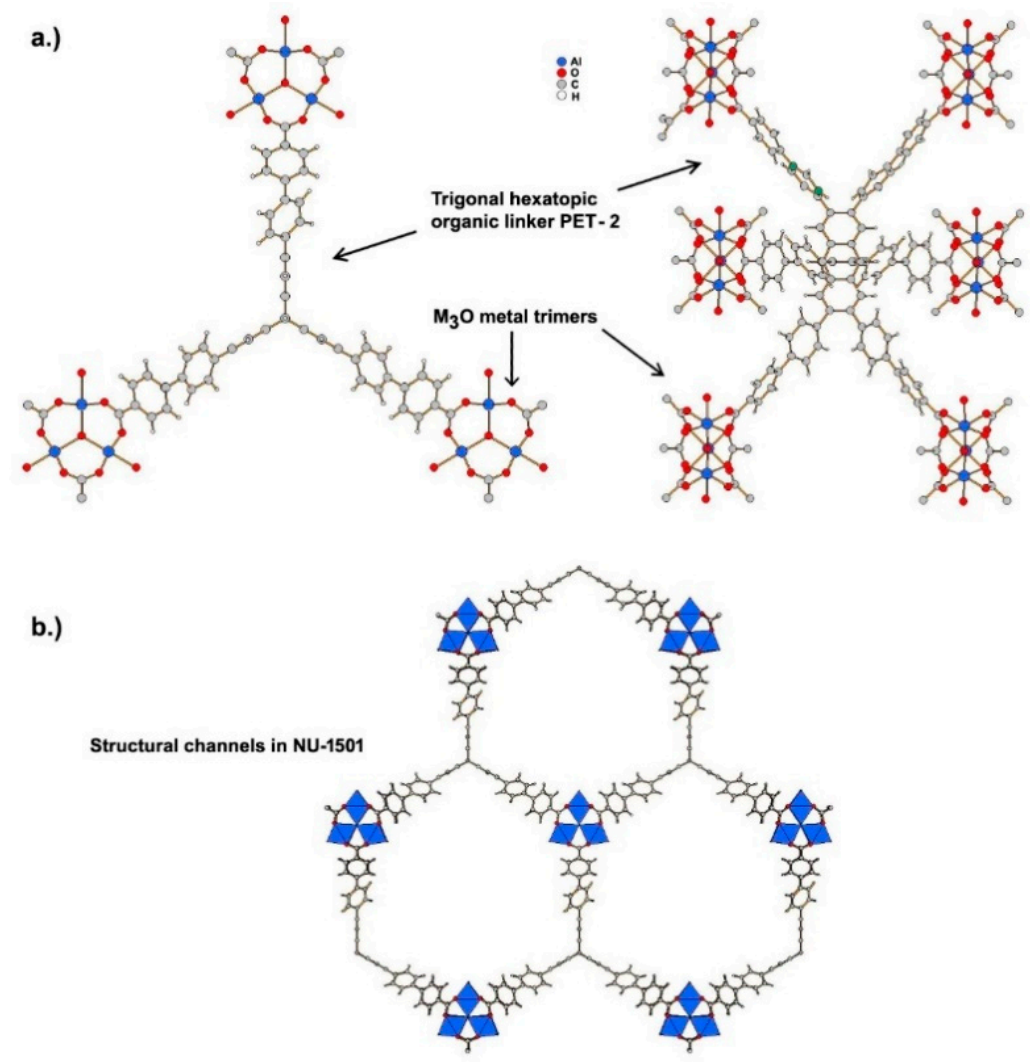

Figure 6. (a) Coordination of peripherally extended triptycene $\left(\mathrm{H}_{6} \mathrm{PET}-2\right)$ to metal cations forming $\mathrm{M}_{3} \mathrm{O}$ metal trimers. (b) Structural channels in NU-1501 viewed along $c$ axis.

\section{Current Approaches to Increasing Hydrogen Adsorption in MOFs}

Unfortunately, no MOFs currently satisfy the proposed DoE target under ambient conditions. The porous MOFs adsorb molecular hydrogen physically; therefore, $\mathrm{H}_{2}$ adsorption capacity sharply decreases at higher temperatures. To predict hydrogen adsorption isotherms, GCMC simulations over a wide range of pressures at $77 \mathrm{~K}$ have been performed for a series of IRMOFs [81]. The obtained theoretical results suggest the existence of three adsorption modes at $77 \mathrm{~K}:(1)$ at low pressure $\left(\sim 1\right.$ bar of $\left.\mathrm{H}_{2}\right)$, the $n_{a}$ value is proportional to the value of $Q_{s t} ;(2)$ at $\sim 30$ bar of $\mathrm{H}_{2}$, the $n_{a}$ value is proportional to $A_{s}$; and (3) at $\sim 120$ bar of $\mathrm{H}_{2}$, the $n_{a}$ value is proportional to $V_{a}$. Due to the very weak adsorption energy between MOFs and $\mathrm{H}_{2}$ molecules, the correlations obtained for the total adsorbed amount of hydrogen at $77 \mathrm{~K}$ [81] could not be similarly exploited for those at $298 \mathrm{~K}$ [82]. Even at low $P\left(\mathrm{H}_{2}\right)$ at $298 \mathrm{~K}$, the $n_{a}$ value mainly correlates with the $V_{a}$ value, whereas the $n_{\sigma}$ value again correlates well with $Q_{s t}$. At high pressure, the $n_{a}$ value correlates better with $A_{s}$ than with $V_{a}$. The authors of $[81,82]$ predicted that a reasonable value of $\mathrm{H}_{2}$ adsorption capacity, such as $9 \mathrm{wt} \%$ of $\mathrm{H}_{2}$, could be obtained with MOFs that can provide the value of $Q_{s t}$ within the range of $15-25 \mathrm{~kJ} \cdot \mathrm{mol}^{-1}$ with the $V_{a}$ value of $\sim 2.5 \mathrm{~cm}^{3} \cdot \mathrm{g}^{-1}$ and porosity of $\sim 85 \%$. 
For MOF-5, the measured adsorption isotherm at $77 \mathrm{~K}$ showed type I behavior [59] with $\mathrm{H}_{2}$ adsorption capacity of $4.7 \mathrm{wt} \%$ of $\mathrm{H}_{2}$ at $P\left(\mathrm{H}_{2}\right)=50$ bar [83]. The experimentally observed fast hydrogen adsorption at low hydrogen pressure indicates favorable sorption interactions between the MOF-5 and $\mathrm{H}_{2}$ molecules [28]. The hydrogen adsorption isotherm at $298 \mathrm{~K}$ was approximately linear because the MOF- 5 framework was under-saturated with gas within the range of 5-20 bar of $\mathrm{H}_{2}$. Recently, it was found that the ultramicroporous MOF, NU-1501-Al, exhibits high values for both gravimetric and volumetric BET areas $\left(7310 \mathrm{~m}^{2} \cdot \mathrm{g}^{-1}\right.$ and $2060 \mathrm{~m}^{2} \cdot \mathrm{cm}^{-3}$, respectively [80]). These were considered the main reasons for the high value of hydrogen storage capacity $\left(14.0 \mathrm{wt} \%\right.$ and $\left.46.2 \mathrm{~g} \cdot \mathrm{dm}^{-3}\right)$ under a combined $T$ and $P\left(\mathrm{H}_{2}\right)$ change from $77 \mathrm{~K}$ and 100 bar to $160 \mathrm{~K}$ and 5 bar.

\subsection{Factor of the Surface Area and Pore Volume}

A linear relationship between the $\mathrm{H}_{2}$ adsorption capacity at $77 \mathrm{~K}$ and the $A_{s}$ value has been confirmed in numerous publications [40]. As a result of the $V_{a}$ value being proportional to $A_{s}$, higher values of both $V_{a}$ and $A_{s}$ are recommended to improve hydrogen adsorption in MOF at $77 \mathrm{~K}$. The adsorption capacity at $77 \mathrm{~K}$ and 1 bar of $\mathrm{H}_{2}$ is related to the $A_{s}$ values within the range of $100-2000 \mathrm{~m}^{2} \cdot \mathrm{g}^{-1}$ and is not correlated in the case of higher $A_{s}$ values. This may be because the sorbent surface cannot be fully covered by $\mathrm{H}_{2}$ molecules at these high $A_{s}$ and low $P\left(\mathrm{H}_{2}\right)$ values. In addition, it is most likely that the $\mathrm{H}_{2}$ molecules will preferentially bind on the most thermodynamically favorable sites in MOFs with the largest affinity to hydrogen. In the porous MOFs at a low pressure of $77 \mathrm{~K}, \mathrm{H}_{2}$ adsorption may be affected by ligand functionalization, catenation, open metal sites, and pore size, whereas high-pressure $\mathrm{H}_{2}$ adsorption is directly proportional to the $A_{s}$ value.

The scaffolding-like nature of MOF-5 and IRMOFs results in remarkably high values of $A_{s}\left(2500-3000 \mathrm{~m}^{2} \cdot \mathrm{g}^{-1}\right.$ [28]). The crystal structure of MOF- 5 serves as an ideal 3D location to adsorb hydrogen gas because the organic linkers are isolated from each other and accessible from all sides to adsorb the $\mathrm{H}_{2}$ molecules. MOF- 5 samples prepared with different characteristics (low crystallinity, high crystallinity, interwoven, and interwoven with incorporated MWCNTs) have been studied to evaluate their effects on pore characteristics (determined by the BET approach for $\mathrm{N}_{2}$ adsorption at $77 \mathrm{~K}$ and $p / p_{0}$ value of 0.98 ) and $\mathrm{H}_{2}$ adsorption (measured at $77 \mathrm{~K}$ and 1 bar of $\mathrm{H}_{2}$ ) [84]. The obtained results confirmed that higher crystallinity in MOF-5 leads to higher $A_{s}$ and $V_{a}$ values, in addition to higher $\mathrm{H}_{2}$ adsorption capacity and thermal stability (Table 1 ). The interwoven MOF-5 samples showed an ultramicroporous structure and reached 1.7 and $2.0 \mathrm{H}_{2} \mathrm{wt} \%$, and an increase in the decomposition temperature, $T_{\text {dec }}$, to 773 and $783 \mathrm{~K}$, respectively.

Table 1. Specific surface area, pore volume, and $\mathrm{H}_{2}$ adsorption for structurally modified MOF-5. Adapted with permission from [84]. Copyright (C) 2012, Elsevier. B.V. All rights reserved.

\begin{tabular}{cccccc}
\hline MOF-5 Sample & $\begin{array}{c}A_{s \boldsymbol{s}} \\
\mathbf{m}^{\mathbf{2}} \cdot \mathbf{g}^{\mathbf{- 1}}\end{array}$ & $\begin{array}{c}\boldsymbol{V}_{\boldsymbol{a}} \\
\mathbf{c m}^{\mathbf{3}} \cdot \mathbf{g}^{\mathbf{- 1}}\end{array}$ & $\begin{array}{c}\text { Pore Size, } \\
\mathbf{\AA}\end{array}$ & $\begin{array}{c}\mathbf{w t} \% \mathbf{~ o f} \\
\mathbf{H}_{\mathbf{2}}\end{array}$ & $\begin{array}{c}\mathbf{T}_{\mathbf{d e c}} \\
\mathbf{K}\end{array}$ \\
\hline Low-crystalline & 2050 & 0.88 & $\sim 6$ and $\sim 13$ & 1.2 & 711 \\
High-crystalline & 3400 & 1.42 & $\sim 7$ and $\sim 14$ & 1.3 & 755 \\
Interwoven & 1010 & 0.51 & $\sim 6$ & 1.7 & 773 \\
$\begin{array}{c}\text { Interwoven with } \\
\text { incorporated MWCNTs }\end{array}$ & 1170 & 0.57 & $\sim 6$ & 2.0 & 783 \\
\hline
\end{tabular}

The factors of surface area and pore volume are well recognized to have an impact on hydrogen adsorption. MOFs with very large surface areas usually show the highest hydrogen adsorption capacities. Typically, MOF materials with high BET areas, e.g., MOF210 [82] and DUT-60 [85], show very high gravimetric adsorption capacities. Alternatively, as reported recently, balancing volumetric and gravimetric uptake must be considered for the development of ideal hydrogen adsorbents [80]. 


\subsubsection{Length of Organic Linkers}

Previous research has shown that, for a given crystal structure of MOFs, the $A_{s}$ value can be increased using longer ligands (linkers). For example, BBC $\left(4,4^{\prime}, 4^{\prime \prime}\right.$-[benzene1,3,5-trilytris(benzene-4,1-diyl)]tribenzoate) may be considered to a longer model of BTB (4,4', ,4'-benzene-1,3,5-triyl-tribenzoate). MOF-200, which comprises the BBC linker, demonstrates an $A_{s}$ value of $4520 \mathrm{~m}^{2} \cdot \mathrm{g}^{-1}$, and MOF-177 with the BTB linker has an $A_{s}$ value of $4750 \mathrm{~m}^{2} \cdot \mathrm{g}^{-1}$ (both using the BET method) [86]. A thorough comparison of isostructural UiO-66 and UiO-67 was made in [87]. These MOFs are constructed from $\mathrm{Zr}_{6} \mathrm{O}_{4}(\mathrm{OH})_{4}$ nodes, and organic linkers 1,4-benzene-dicarboxylate and 4,4'-biphenyldicarboxylate for UiO-66 and UiO-67, respectively. Resulting from of the longer linker in the case of UiO-67, the value of $A_{s}$ (Langmuir) was $2483 \mathrm{~m}^{2} \cdot \mathrm{g}^{-1}$, which is higher than that value of $1281 \mathrm{~m}^{2} \cdot \mathrm{g}^{-1}$ in the case of UiO-66. A similar effect was observed for the $V_{a}$ value $\left(0.85 \mathrm{vs} .0 .43 \mathrm{~cm}^{3} \cdot \mathrm{g}^{-1}\right)$. As a consequence, the hydrogen adsorption capacity measured at $77 \mathrm{~K}$ and 38 bar of $\mathrm{H}_{2}$ was almost twice as high for UiO-67 (4.6 wt\%) as for UiO-66 (2.4 wt\%). A "ligand-truncation" strategy was studied in [88]. The idea was to reduce the $C_{3}$-symmetry of the $\mathrm{H}_{6} \mathrm{PHB}$ linker $\left(3,3^{\prime}, 3^{\prime \prime}, 5,5^{\prime}, 5^{\prime \prime}\right.$-pyridyl-1,3,5-triylhexabenzoic acid) to the $C_{2}$-symmetry of $\mathrm{H}_{4} \mathrm{~L}$ (2,6-di $\left(3^{\prime}, 5^{\prime}\right.$ dicarboxylphenyl)pyridine) in GDMU-2. Therefore, this MOF changed the chemical composition from $\left[\mathrm{Cu}_{4}\left(\mu_{2}-\mathrm{O}\right)(\mathrm{PHB})_{1 \cdot 5}\left(\mathrm{H}_{2} \mathrm{O}\right)_{2}\right] \cdot(\mathrm{DMF})_{5}\left(\mathrm{H}_{2} \mathrm{O}\right)_{4}$ to $\left\{\left[\mathrm{Cu}_{2}(\mathrm{~L})\left(\mathrm{H}_{2} \mathrm{O}\right)_{6}\right]_{n} \cdot 4 \mathrm{nDMF}\right\}$. The new MOF with the $\mathrm{H}_{4} \mathrm{~L}$ linker preserved the paddle wheel cluster, and the alignment of open metal sites and functional sites, similar to those observed in the GDMU-2. Hydrogen adsorption measured at $77 \mathrm{~K}$ and 1 bar of $\mathrm{H}_{2}$ for GDMU-2 was higher than that for the new MOF (240.7 vs. $\left.193.0 \mathrm{~cm}^{3} \cdot \mathrm{g}^{-1}\right)$.

It was recommended that the increase in the $n_{a}$ value could be anticipated because IRMOFs have similar but larger organic linkers [28]. For comparison of such an organic linker function in IRMOFs, experimental data on pore characteristics and $\mathrm{H}_{2}$ adsorption collected in [40] are shown in Table 2.

Table 2. Surface area (BET), pore volume, and $\mathrm{H}_{2}$ adsorption capacity at $77 \mathrm{~K}$ and 1 bar of $\mathrm{H}_{2}$ for IRMOFs.

\begin{tabular}{|c|c|c|c|c|}
\hline \multirow[b]{2}{*}{ MOF Sample } & \multirow[b]{2}{*}{ Organic Linker } & \multicolumn{2}{|c|}{ Pore Characteristics } & \multirow{2}{*}{$\begin{array}{c}\mathrm{H}_{2} \\
\text { Adsorption, } \\
\mathbf{w} \mathbf{t} \%\end{array}$} \\
\hline & & $\begin{array}{c}A_{s} \\
\mathrm{~m}^{2} \cdot \mathrm{g}^{-1}\end{array}$ & $\begin{array}{c}V_{a} \\
\mathrm{~cm}^{3} \cdot \mathrm{g}^{-1}\end{array}$ & \\
\hline IRMOF-1 & 1,4-benzenedicarboxylate & 3362 & - & 1.32 \\
\hline IRMOF-2 & 2-bromobenzene-1,4-dicarboxylate & 1722 & 0.88 & 1.21 \\
\hline IRMOF-3 & 2-aminobenzene-1,4-dicarboxylate & 2446 & 1.07 & 1.42 \\
\hline IRMOF-6 & 1,2-dihydrocyclobutabenzene-3,6-dicarboxylate & 2476 & 1.14 & 1.48 \\
\hline IRMOF-8 & Naphthalenedicarboxylate & 890 & 0.45 & 1.45 \\
\hline IRMOF-9 & $4,4^{\prime}$-biphenyldicarboxylate & 1904 & 0.9 & 1.17 \\
\hline IRMOF-11 & 4,5,9,10-tetrahydropyrene-2,7-dicarboxylate & - & - & 1.62 \\
\hline IRMOF-13 & pyrene-2,7-dicarboxylate & 1551 & 0.73 & 1.73 \\
\hline IRMOF-16 & p-terphenyl-4,4'-dicarboxylate & - & - & -- \\
\hline IRMOF-18 & 2,3,5,6-tetramethylbenzene-1,4-dicarboxylate & 1501 & - & 0.89 \\
\hline IRMOF-20 & thieno[3,2-b]thiophen-2,5-dicarboxylate & 3409 & 1.53 & 1.35 \\
\hline
\end{tabular}

The number of aromatic benzene rings may also influence the hydrogen sorption, as determined from the study of IRMOFs, in which the $\mathrm{Zn}_{4} \mathrm{O}\left(\mathrm{CO}_{2}\right)_{6}$ cluster is linked by chemically diverse organic linkers with a different number of benzene rings in the linker. The hydrogen sorption changed within the range of $0.89-1.73 \mathrm{wt} \% \mathrm{H}_{2}$ [89]. In the case of MOF-177, which has a mixed $(3,6)$-connectivity due to the tritopic linkage of BTB, the hydrogen adsorption capacity was estimated to be $1.25 \mathrm{wt} \% \mathrm{H}_{2}$. A crucial role of the organic linker was inconsistent with the model in which the metal oxide units dominate the sorption behavior in MOFs [90]. For example, IRMOF-20 and MOF-177 have a relatively low proportion of metal oxide to organic linker but, within the range of $70-80 \mathrm{bar} \mathrm{H}_{2}$, they demonstrated hydrogen adsorption of 6.7 and $7.5 \mathrm{wt} \%$, respectively. 
The results obtained for IRMOFs confirmed that the organic linker geometry, particularly the length, has a direct influence on the pore size, and hence the surface area of MOFs. In addition, when the $A_{s}$ values correlate with the $n_{a}$ values, the $\mathrm{H}_{2}$ adsorption capacity should depend on the length of the organic linkers. Therefore, the values of hydrogen adsorption capacity for IRMOF-6, IRMOF-8, IRMOF-11, and IRMOF-13 is considerably higher than that for IRMOF-1, IRMOF-2, IRMOF-9, and IRMOF-20 (Table 2). The elongation of the organic linker is limited, and may be collapsed in the case of the flexible MOF porous structure formed with long linkers. This behavior often leads to framework interpenetration, which results in a considerably reduced $A_{s}$ value.

\subsubsection{Catenation Process}

From a thermodynamic perspective, the value of surface energy must be as low as possible to form a compact structure of the material. Therefore, when large pores in an MOF from a long organic linker are anticipated using only the geometrical calculation, an interweaving or interpenetration of the MOF framework may occur in practice. Interweaving and interpenetration are considered to be two types of the catenation process (bonding of atoms of the same element into a chain) where, respectively, a minimal and maximal displacement occurs between the catenated frameworks [91,92]. In an experimental work [93], it was proposed that catenation of MOFs may be controlled by adding a template during the solvothermal MOF synthesis (e.g., the oxalic acid used as a template promotes a non-catenated MOF framework). Using a brominated and non-brominated ligand, in which a non-catenated and catenated MOF framework was produced, the authors of [94] concluded that catenation may be controlled by the organic linker design. As a result of the synthesis of organic linkers and their organization in the MOF structure depending on the reaction parameters (e.g., the precursor concentration, temperature, and time of stirring), the catenation process in a different form is strongly guided by the MOF synthesis conditions $[95,96]$.

It is obvious that catenation directly affects the $\mathrm{H}_{2}$ adsorption in MOFs. The copper paddle wheel node and the TATB linker $\left(4,4^{\prime}, 4^{\prime \prime}\right.$-s-triazine2,4,6-triyltribenzoate) are the building units for both porous coordination networks (PCNs), catenated PCN-6 and noncatenated PCN-60, and their general formula is $\mathrm{Cu}_{3}(\mathrm{TATB})_{2}$ [93]. After sample activation at $323 \mathrm{~K}$, the hydrogen adsorption capacity at $77 \mathrm{~K}$ and 1 bar of $\mathrm{H}_{2}$ was 1.74 and $1.35 \mathrm{wt} \%$ for PCN-6 and PCN-60, whereas after activation at $423 \mathrm{~K}$, these values increased to 1.9 and $1.62 \mathrm{wt} \%$, respectively. The larger improvement in $\mathrm{H}_{2}$ adsorption for the non-catenated PCN-60 was explained by the open metal sites, which were blocked in the catenated PCN-6. Inelastic neutron scattering (INS) experiments suggested that in these MOFs, the open metal sites are most favorable for the $\mathrm{H}_{2}$ molecules, and at higher $P$ values, the interaction between the $\mathrm{H}_{2}$ molecules and the organic linkers becomes stronger in the catenated PCN-6. The INS results were in good agreement with the high pressure $\mathrm{H}_{2}$ adsorption measurements at 77 or $298 \mathrm{~K}$ and 50 bar of $\mathrm{H}_{2}$ (Table 3). The experimental $n_{a}$ and $n_{\sigma}$ values confirmed higher $\mathrm{H}_{2}$ adsorption for the catenated PCN-6 than the noncatenated PCN-60. In addition to PCN-6 and PCN-60, high adsorption capacities were determined for the compound PCN-610/NU-100. Ahmed et al. [48] undertook a systematic assessment of published databases of real and hypothetical MOFs, and screened nearly half a million metal-organic frameworks, which were examined computationally. The most promising materials identified computationally were subsequently synthesized and characterized experimentally. For these three compounds, the authors reported hydrogen usable capacities for the pressure range of 5-100 bar. Of these compounds, the highest hydrogen usable gravimetric capacity was found for PCN-610/NU-100, with a value of $10.1 \mathrm{wt} \%$ [48]. 
Table 3. Values of surface excess and the total adsorbed amount of hydrogen (experimentally obtained at 77 or $298 \mathrm{~K}$ and 50 bar of $\mathrm{H}_{2}$ ) for catenated PCN-6 and non-catenated PCN-60.

\begin{tabular}{|c|c|c|c|c|}
\hline \multirow{2}{*}{ Temperature, K } & \multicolumn{2}{|c|}{ Catenated PCN-6 } & \multicolumn{2}{|c|}{ Non-Catenated PCN-60 } \\
\hline & $n_{a}, \mathrm{wt} \%$ of $\mathrm{H}_{2}$ & $n_{\sigma}, \mathrm{wt} \%$ of $\mathrm{H}_{2}$ & $n_{a}, \mathrm{wt} \%$ of $\mathrm{H}_{2}$ & $n_{\sigma}, \mathrm{wt} \%$ of $\mathrm{H}_{2}$ \\
\hline 77 & 8.7 & 6.7 & 5.5 & 4.0 \\
\hline 298 & 1.5 & 0.9 & 0.8 & 0.4 \\
\hline
\end{tabular}

Similar results were obtained for the catenated $\mathrm{Zn}_{4} \mathrm{O}(\mathrm{dcdEt})_{3}$ and $\mathrm{Zn}_{4} \mathrm{O}(\mathrm{dcbBn})_{3}$ (dcdEt=6,6'-dichloro-2,2' -diethoxy-1,1'-binaphthyl-4,4'-dibenzoate; dcbBn=6,6'-dichloro2,2'-dibenzyloxy-1,1'-binaphthyl-4,4'-dibenzoate) [97]. Their four-fold interpenetrated frameworks adsorbed about $1.0 \mathrm{wt} \%$ of $\mathrm{H}_{2}$ at $298 \mathrm{~K}$ and $P\left(\mathrm{H}_{2}\right)=48$ bar. This was explained by a smaller pore size, which increased the "guest-host" interactions. When MOFs are catenated too much, they show very low $\mathrm{H}_{2}$ adsorption. For example, the three-fold interpenetrated frameworks of $\left[\mathrm{Cu}_{3}\left(4,4^{\prime}-\mathrm{bpy}\right)_{1 \cdot 5}(2,6-\mathrm{NDC})_{3}\right]_{\mathrm{n}}((\mathrm{bpy}=$ bipyridine $) ; \mathrm{NDC}=$ naphthalenedicarboxylate) $)$ and $\left\{\left[\mathrm{Cu}(\mathrm{bpe})_{0} \cdot 5(2,6-\mathrm{NDC})\right] \cdot 0.5 \mathrm{H}_{2} \mathrm{O}\right\}_{\mathrm{n}}$ (bpe $=1,2$-bis(4-pyridyl)ethane) showed low $\mathrm{H}_{2}$ adsorption capacities at $77 \mathrm{~K}$ and 15 bar of $\mathrm{H}_{2}(0.88$ and $0.96 \mathrm{wt} \%$, respectively) [98]. This may be due to negligible $A_{s}$ values estimated by the Langmuir method, i.e., 113 and $337.5 \mathrm{~m}^{2} \cdot \mathrm{g}^{-1}$, for $\left[\mathrm{Cu}_{3}\left(4,4^{\prime}-\mathrm{bpy}\right)_{1 \cdot 5}(2,6-\mathrm{NDC})_{3}\right]_{\mathrm{n}}$ and $\left\{\left[\mathrm{Cu}(\mathrm{bpe})_{0.5}(2,6-\right.\right.$ $\left.\mathrm{NDC})] \cdot 0.5 \mathrm{H}_{2} \mathrm{O}\right\}_{\mathrm{n}}$, respectively.

Therefore, using the catenation process, the pore characteristics may be altered, and hence the hydrogen adsorption capacity of MOFs can be changed. The authors of [99] concluded that the positive effect of catenation on $\mathrm{H}_{2}$ adsorption in MOFs is due to a strengthened framework and a smaller pore size.

\subsubsection{Different Organic Linkers}

A combination of two types of organic linker within the same MOF structure could be another approach to increase the pore characteristics of MOFs. For example, the SNU-6 framework was constructed from the BPnDC (4,4'-benzophenone dicarboxylate) ligand and the bpy $\left(4,4^{\prime}\right.$-bipyridine) ligand, together with $\mathrm{Cu}^{2+}$ nodes [100]. This MOF was characterized by large pores (the pore diameter of $18.2 \AA$ ), and the $A_{s}$ values obtained by the BET and Langmuir methods were 2590 and $2910 \mathrm{~m}^{2} \cdot \mathrm{g}^{-1}$, respectively. The hydrogen adsorption capacity at $77 \mathrm{~K}$ and 1 bar of $\mathrm{H}_{2}$ was relatively low (1.68 wt\%); however, at high pressure $\left(77 \mathrm{~K}\right.$ and 70 bar of $\left.\mathrm{H}_{2}\right)$, the $n_{a}$ and $n_{\sigma}$ values were 10.0 and $4.87 \mathrm{wt} \%$, respectively. The authors of the work [101] used coordination copolymerization of organic linkers with identical functional coordination but different topologies. BET and Langmuir $A_{s}$ values of 5200 and $6060 \mathrm{~m}^{2} \cdot \mathrm{g}^{-1}$, respectively, were obtained for the UMCM-2 framework with the $\left[\mathrm{Zn}_{4} \mathrm{O}\left(\mathrm{T}_{2} \mathrm{DC}\right)(\mathrm{BTB})_{4 / 3}\right]$ formula $\left(\mathrm{T}_{2} \mathrm{DC}=\right.$ thieno[3,2-b]thiophene-2,5-dicarboxylate). It should be noted that these high $A_{s}$ values originated from the novel framework topologies that were hard to obtain using only one type of organic linker. The experimentally obtained $n_{\sigma}$ value was around $6.9 \mathrm{wt} \%$ at $77 \mathrm{~K}$ and 46 bar of $\mathrm{H}_{2}$. In [102], the mixed BTB/NDC and BTE/BPnDC linkers (BTB = 4, $4^{\prime}, 4^{\prime \prime}$-benzene-1,3,5-triyl-tribenzoate; BTE $=4,4^{\prime}, 4^{\prime \prime}$ [benzene-1,3,5-triyl-tris(ethyne-2,1-diyl)]tribenzoate) were used to obtain MOF-205 and MOF-210, respectively. These MOFs were characterized by high BET/Langmuir $A_{s}$ values $\left(4460 / 6170 \mathrm{~m}^{2} \cdot \mathrm{g}^{-1}\right.$ and $6240 / 10,400 \mathrm{~m}^{2} \cdot \mathrm{g}^{-1}$ for MOF-205 and MOF-210, respectively), which positively reflected on the $\mathrm{H}_{2}$ adsorption. For example, for MOF-210, the hydrogen adsorption capacity at $77 \mathrm{~K}$ was $8.6 \mathrm{wt} \%$ at 56 bar of $\mathrm{H}_{2}$ and $17.6 \mathrm{wt} \%$ at 80 bar of $\mathrm{H}_{2}$.

Approaches using different organic linkers have recently been developed with a mixed-matrix hybrid strategy to provide a tool for facile characterization of molecular transport in MOFs. For example, in [103], incorporation of the MOF crystals into polymers resulted in hybrid membranes with excellent molecular sieving properties. The improved membrane performance resulted from precise control of the organic linkers in the MOF, which delimited the entrance to the pores. 


\subsubsection{Flexible Organic Linkers}

Since 2003, significant interest has been directed towards dynamic MOFs with flexible organic linkers [104-110]. Dynamic MOFs can respond to external conditions (e.g., T, $P$, electric or magnetic fields, and chemical insertion) and reversibly change their channels by a large magnitude while maintaining the same or similar topologies. Therefore, this type of MOF is often associated with reversible transformations between the expansion and the contraction states [105-107], which are called the "breathing" [108] or "sponge" [109] effect. For 3D dynamic MOFs, three situations have been distinguished (Figure 7) [111]. As a result of the interlayer extension and shortening, reversible transformations may occur using suitable flexible pillars (class a, Figure 7a). Class b corresponds to sponge-like dynamic behavior (Figure $7 \mathrm{~b}$ ). Finally, when interpenetrated high-packed frameworks occur (class c), the introduction of guest molecules promotes the sliding of one framework (Figure 7c).

(a)

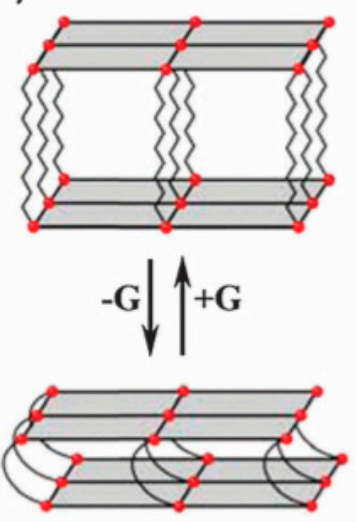

(b)

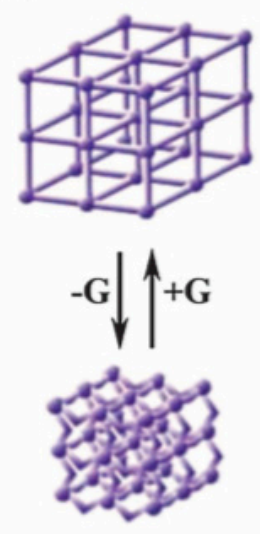

(c)

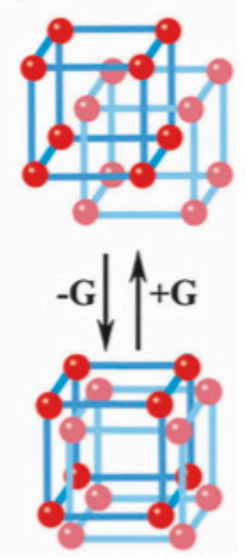

Figure 7. Three classes of breathing in dynamic 3D MOFs categorized by Kitawaga and Uemura. (a) In the case of pillared-layer MOFs, the reversible phases because of interlayer elongation and shortening could be realized using suitable flexible pillars. (b) For expanding and shrinking MOFs, they can show sponge-like dynamic behavior. (c) In interpenetrated grids which are densely packed in the absence of guests an introduction of molecules generates a sliding of one network. Reprinted with permission from [111]. Copyright (C 2014, Royal Society of Chemistry. All rights reserved.

In the case of pillaring the layer using flexible linkers (class a), reversible extension and shortening of the pillars in the interlayers result in two stable MOF states. For example, in the layered $\gamma-\mathrm{ZrPO}_{4}\left[\mathrm{O}_{2} \mathrm{P}(\mathrm{OH})_{2}\right] \cdot 2 \mathrm{H}_{2} \mathrm{O}$ frameworks, the $\left[\mathrm{O}_{2} \mathrm{P}(\mathrm{OH})_{2}\right]$ groups can be substituted with different alkane diphosphonate ligands. The $\mathrm{ZrPO}_{4}\left[\mathrm{O}_{2} \mathrm{P}(\mathrm{OH})_{2}\right]_{1-x}$ $\left(\mathrm{O}_{2} \mathrm{POH}-\left(\mathrm{CH}_{2}\right)_{n} \mathrm{HOPO}_{2}\right)_{x / 2} \cdot \mathrm{mH}_{2} \mathrm{O}(n=4-16 ; 0<x<1)$ materials, in which the degree of pillaring $(x)$ was tuned by the reaction time, were synthesized in $[106,109]$. The reversible transformations were observed for low $x$ values, where two different alkanediphosphonic chains were separated by the $\left[\mathrm{O}_{2} \mathrm{P}(\mathrm{OH})_{2}\right]$ groups in the direction parallel to the layer. For example, fully hydrated 1,10-decanediphosphonate chains were extended (Figure 8a), whereas the dehydrated chains were shortened (Figure $8 b$ ). In practice, these transformations were reversible because the originally expanded framework could be prepared again via the chemical insertion of solvent molecules.

A pillared-layer $\left\{\left[\mathrm{Co}_{2} \text { (epda) }\right)_{2}\right.$ (etbipy) $\left.\left.\left(\mathrm{H}_{2} \mathrm{O}\right)_{2}\right] \cdot 3 \mathrm{H}_{2} \mathrm{O}\right\}_{\mathrm{n}}$ framework synthesized from $\mathrm{H}_{2}$ epda (5-ethyl-pyridine-2,3-dicarboxylic acid) and etbipy (1,2-Bi(4-pyridyl)ethane) was introduced as a dynamic MOF in [111]. The framework formation was perfected by employing the rigid $\mathrm{H}_{2}$ epda linker and $\mathrm{Co}^{2+}$ cations to form 2D networks, and the flexible etbipy linkers as pillaring ligands. The reversible extension and shortening of pillars were estimated to result in a 9\% difference in the cell volume, while the crystal structure of expansion and contraction states remained unchanged (Figure 9). The decrease in the interlayer distance between the 2D Co-carboxylate layers from 15.77 to $14.35 \AA$ was 
attributed to the rotation of the $\mathrm{C}-\mathrm{C}$ single bonds of the flexible etbipy ligands, resulting in the relative gliding between the neighboring layers. The two pyridyl rings in the etbipy linker are almost perpendicular to each other in the expansion state, whereas they are almost coplanar in the contraction state.

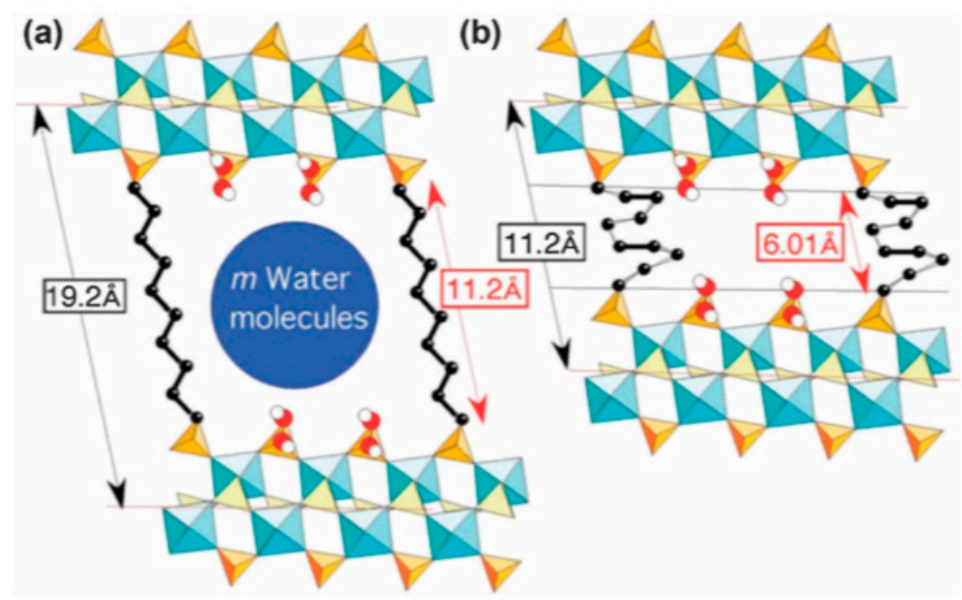

Figure 8. A schematic of the fully hydrated (a) and dehydrated (b) phosphate/diphosphonate showing the contraction of the carbon chain. Zr octahedra, colored in blue; phosphate tetrahedra, yellow; $\mathrm{O}, \mathrm{H}$, and $\mathrm{C}$ atoms are shown in red, white, and black, respectively. Reprinted with permission from [108]. Copyright @ 2009, Royal Society of Chemistry. All rights reserved.

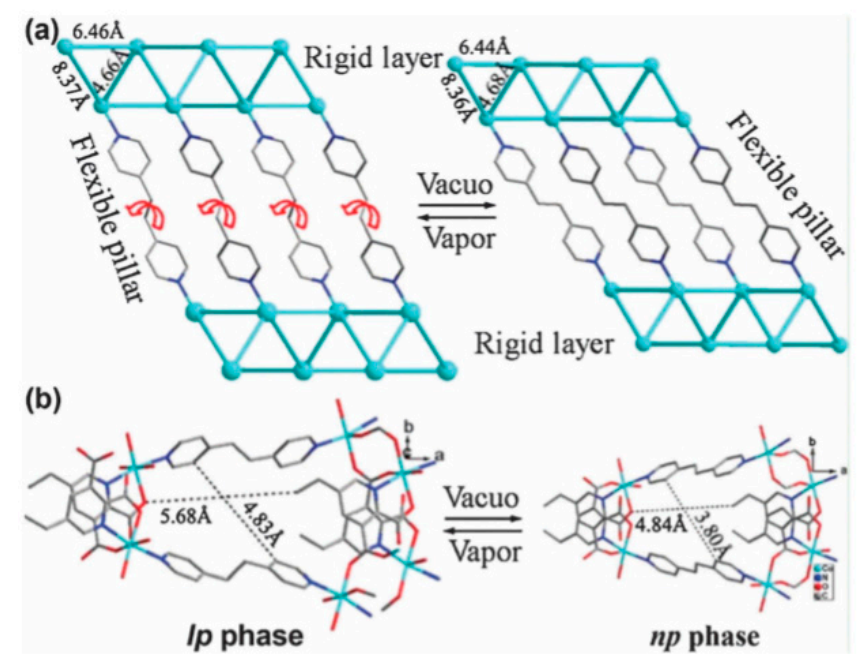

Figure 9. Structures of the pillared $\left\{\left[\mathrm{Co}_{2}(\text { epda })_{2}(\text { etbipy })\left(\mathrm{H}_{2} \mathrm{O}\right)_{2}\right] \cdot 3 \mathrm{H}_{2} \mathrm{O}\right\}_{n}$ framework (a) showing the rotation of the flexible ligand upon desolvation. The front view of the channels (b) showing reversible expansion ( $l p$ phase) and contraction ( $n p$ phase) of the pores. Only Co atoms (blue balls) for each layer are shown for clarity. Reprinted with permission from [111]. Copyright (C) 2012, Royal Society of Chemistry. All rights reserved.

A systemic synthesis and characterization of a series of MOFs with the pillared layer structure was carried out in [112]. The $\left[\mathrm{Zn}_{4}(\mathrm{bpta})_{2}\left(\mathrm{H}_{2} \mathrm{O}\right)_{2}\right]\left(\mathrm{H}_{4}\right.$ bpta $=1,1^{\prime}$-biphenyl-2,2',6,6'tetracarboxylic acid) layers were connected by length-controllable bipyridine pillars. The authors developed a synthetic strategy that allowed systematic variation of the pillar to construct open frameworks with a similar structure. It was concluded that pore design could be adjusted by the selection of pillar ligands, hence leading to different hydrogen adsorption properties. The results obtained indicated that the activation process of these MOFs could affect the $Q_{s t}$ value. 
The hydrogen adsorption analysis of three flexible sulfur-containing MOF materials named M-URJC-n (M = Co, Cu, Zn) based on the 5,5'-thiodiisophthalic acid linker $\left(\mathrm{H}_{4}\right.$ TBTC) showed that these compounds display a gate-opening type adsorption mechanism at low pressures, attributed to the flexible nature of the ligand [113]. The hydrogen adsorption capacities of the compounds were not high, with levels of $2.81,2.21$, and $1.99 \mathrm{wt} \%$, for Co-, $\mathrm{Cu}-$, and $\mathrm{Zn}$ modification, respectively, at $77 \mathrm{~K}$ and up to $18 \mathrm{bar}$, and $0.12,0.14$, and $0.13 \mathrm{wt} \%$, at $298 \mathrm{~K}$ and $170 \mathrm{bar}$, due to the presence of flexible ligands. These compounds showed an interesting gate-opening type adsorption mechanism. Considering the flexibility and the dynamic nature of the new structures, these compounds are candidates for applications such as hydrogen selective adsorption and gas separation processes, including hydrogen purification in precombustion mixtures of $\mathrm{H}_{2} / \mathrm{CO}_{2}$ [113].

A series of dynamic MOFs with ditopic organic linkers, which are the ligands capable of coordination at two separate sites and allow the creation of well-ordered extended complexes containing different cations, was prepared in [114-119]. The sponge-like dynamic mechanism is activated by rotation around the $\mathrm{O}-\mathrm{O}$ axis of the carboxylate linker, which acts as a "kneecap" for the dynamic MOFs, either through a twisting or a bending mode. In combination with the integration of the "kneecap" into the interface between the metallic node and the organic linker, this approach may be used directly for the linkers themselves while keeping the MOF skeleton stable. In a recent review [120], synthesis of MOFs with flexible organic linkers was considered to be a promising means to shift $\mathrm{H}_{2}$ adsorption to higher pressures. Preparation of MOFs with the "breathing" effect, which gradually adsorb hydrogen gas with an increase in $P\left(\mathrm{H}_{2}\right)$, can transfer physical sorption of $\mathrm{H}_{2}$ in MOFs significantly closer to the general requirements of hydrogen storage material.

\subsection{Factor of Isosteric Enthalpy of Hydrogen Adsorption}

Among MOFs with high $A_{s}$ values, some of the MOF examples have high values of hydrogen adsorption capacity, but only at cryogenic temperature. In practice, the hydrogen adsorption capacity at moderate temperatures designed by DoE falls to less than 1/10 of the value obtained at $77 \mathrm{~K}$, and the $Q_{s t}$ values in most porous MOFs is within the range of $5-10 \mathrm{~kJ} \cdot \mathrm{mol}^{-1}[121,122]$. As a result of physical sorption of $\mathrm{H}_{2}$ molecules, van der Waals interaction between $\mathrm{H}_{2}$ molecules and the pore surface of MOFs is very weak. To increase the interaction at the ambient temperature, two recommendations have been made: (1) strong adsorption sites incorporated into the pores; and (2) optimization of the internal surface of MOF. In practice, creation of open metal sites, introduction of cations generating a strong electrostatic field within the cavities, doping with metal ions, infiltration of metal nanoparticles, and organic linker functionalization have been used to increase molecular hydrogen affinity to MOFs. In [123], it was concluded that MOFs can reach approximately $6 \mathrm{wt} \% \mathrm{H}_{2}$ when they are characterized by a $Q_{s t}$ value of $10-15 \mathrm{~kJ} \cdot \mathrm{mol}^{-1}$ and a free volume within the range of $1.6-2.4 \mathrm{~cm}^{3} \cdot \mathrm{g}^{-1}$, or $Q_{s t}>20 \mathrm{~kJ} \cdot \mathrm{mol}^{-1}$ and a free volume smaller than $1.5 \mathrm{~cm}^{3} \cdot \mathrm{g}^{-1}$. The authors of [124] studied $\mathrm{H}_{2}$ adsorption in an MOF at $298 \mathrm{~K}$ and 1.5 or 120 bar of $\mathrm{H}_{2}$, and measured deliverable capacity as the difference between the $n_{a}$ value at the high and the low hydrogen pressure. Their GCMC calculations suggested that for the maximum $\mathrm{H}_{2}$ delivery at $298 \mathrm{~K}$, the optimal $Q_{s t}$ value must be around $\sim 20 \mathrm{~kJ} \cdot \mathrm{mol}^{-1}$. Other calculations [122] using the same strategy reached the conclusion that at $131 \mathrm{~K}$ and 1.5-100 bar of $\mathrm{H}_{2}$, the optimal $Q_{s t}$ value should be $\sim 6 \mathrm{~kJ} \cdot \mathrm{mol}^{-1}$. In [40], it was concluded that, even when the $Q_{s t}$ values are increased by several units, they did not increase the high pressure $\mathrm{H}_{2}$ adsorption at $77 \mathrm{~K}$, whereas at $298 \mathrm{~K}$ there is a tendency to form a proportional relationship between the $Q_{s t}$ and the $n_{\sigma}$ values.

\subsubsection{Open Metal Sites at Secondary Building Units and Organic Linkers}

It was shown that metal centers unsaturated in coordination, often called "open" or "accessible" metal sites, may increase the $Q_{s t}$ value [125-127]. In practice, the $\mathrm{H}_{2}$ adsorption values measured at $298 \mathrm{~K}$ for MOFs with open metal sites are higher than those for MOFs without open metal sites. In addition, this tendency is pronounced for MOFs with a high 
$A_{s}$ value $\left(>3000 \mathrm{~m}^{2} \cdot \mathrm{g}^{-1}\right)$. Based on experiments involving the introduction of open metal sites in MOFs, several possible approaches have been highlighted: (1) metal nodes with open metal sites; (2) metal clusters coordinating solvent molecules, in which the solvent is removable; (3) organometallic complexes connected with the aromatic organic linkers [126]; (4) metal complexes intercalated through electrostatic forces [126]; and (5) metal cations in the anionic frameworks [127].

Open metal sites in MOFs may be constructed of metal cluster SBUs coordinating solvent molecules, followed by removal of the solvent using thermal treatment. In this case, the SBUs are very often the bimetallic paddle wheel units of $\mathrm{M}_{2}\left(\mathrm{O}_{2} \mathrm{CR}\right)_{4}\left(\mathrm{M}=\mathrm{Cu}^{2+}\right.$, $\left.\mathrm{Zn}^{2+}, \mathrm{Cd}^{2+}\right)$, in which solvent molecules are coordinated at the axial sites. The fluorite-like structure of the $\left[\mathrm{Co}_{4}{ }_{4}\left(\mu-\mathrm{OH}_{2}\right)_{4}(\mathrm{MTB})_{2}\left(\mathrm{H}_{2} \mathrm{O}\right)_{4}\right]_{\mathrm{n}} \cdot 13 \mathrm{nDMF} \cdot 11 \mathrm{nH}_{2} \mathrm{O}$ framework (SNU-15) promotes $3 \mathrm{D}$ channels in which every $\mathrm{Co}^{2+}$ ion coordinates the aqua ligand, and the $\mathrm{Co}-\mathrm{Co}$ distances are 3.550 and $3.428 \AA$. When the coordinated $\mathrm{H}_{2} \mathrm{O}$ molecules are removed, the vacant coordination sites are created on the $\mathrm{Co}^{2+}$ ions. Due to the values of the $\mathrm{Co}-\mathrm{Co}$ distance, $\mathrm{H}_{2}$ molecules can be bonded in a side-on manner that results in the $Q_{s t}$ value of $15 \mathrm{~kJ} \cdot \mathrm{mol}^{-1}$ at zero coverage [124]. The same high $Q_{s t}$ value was found for the $\left[\mathrm{Co}^{\mathrm{II}}{ }_{4}(\mu-\right.$ $\left.\left.\mathrm{OH}_{2}\right)_{4}(\mathrm{MTB})_{2}\right]_{n}(\mathrm{MTB}=$ methanetetrabenzoate) framework (SNU-150') prepared by heating the SNU-15 at $493 \mathrm{~K}$ under a vacuum for $24 \mathrm{~h}$ [128]. The synthesis of MOFs with entatic metal centers, in which it is possible to bind the substrate without ligand removal, may be considered another method to create the open metal sites via the coordination of the solvent molecules by the metal clusters. For example, $\mathrm{PCN}-9$ with the $\mathrm{H}_{2}\left[\mathrm{Co}_{4} \mathrm{O}(\mathrm{TATB})_{8 / 3}\right]$ formula (TATB $=4,4^{\prime}, 4^{\prime \prime}$-s-triazine-2,4,6-triyltribenzoate) holds the square-planar SBU that is $\mathrm{Co}_{4}\left(\mu_{4}-\mathrm{O}\right)$ [129]. The Co atoms in the SBU are five-fold-coordinated with a squarepyramidal geometry, and the position below the square plane formed of the four $\mathrm{O}$ atoms is in an entatic state and ready to bind a molecule to achieve octahedral coordination. This square planar $\mu 4$-oxo bridge found in PCN-9 is a unique phenomenon in MOFs. The $A_{s}$ value, obtained by the Langmuir method, of $1355 \mathrm{~m}^{2} \cdot \mathrm{g}^{-1}$, and the $V_{a}$ value of $0.51 \mathrm{~cm}^{3} \cdot \mathrm{g}^{-1}$ were found for the desolvated PCN-9. Hydrogen adsorption at $77 \mathrm{~K}$ and 1 bar of $\mathrm{H}_{2}$ and the $Q_{s t}$ values for the PCN-9 were $1.53 \mathrm{wt} \%$ and $10.1 \mathrm{~kJ} \cdot \mathrm{mol}^{-1}$, respectively. In a recent work [130], the MOFs $\mathrm{M}_{2}$ ( $m$-dobdc) and the isomeric frameworks $\mathrm{M}_{2}$ (dobdc) ( $\mathrm{M}=\mathrm{Co}$ or $\mathrm{Ni}$; $m$-dobdc4-=4,6-dioxido-1,3-benzenedicarboxylate) were evaluated for their volumetric hydrogen capacity. At $298 \mathrm{~K}$, hydrogen storage of $11.0 \mathrm{~g} \mathrm{H}_{2} \cdot \mathrm{L}^{-1}$ and $23.0 \mathrm{~g} / \mathrm{L}$ with a temperature change between 198 and $298 \mathrm{~K}$ were experimentally confirmed for $\mathrm{Ni}_{2}$ (m-dobdc) within the range of 5-100 bar of $\mathrm{H}_{2}$, whereas the DoE target in 2020 was $30 \mathrm{~g} \mathrm{H}_{2} \cdot \mathrm{L}^{-1}$. These results were explained by the presence of open metal cation sites (highly polarizing $\mathrm{Ni}^{2+}$ ), which strongly interacted with $\mathrm{H}_{2}$ molecules, thus providing their dense packing within $\mathrm{Ni}_{2}$ (m-dobdc).

The open metal sites at organic linkers are also a highly popular approach used to increase the $Q_{s t}$ value. For example, the structures of MOFs constructed from various types of porphyrin complexes are very well known [131-134]. They contain open metal sites with respect to the square-planar coordination plane, therefore the porphyrin-based MOFs may be recommended for effective $\mathrm{H}_{2}$ adsorption [135-138]. The MOFs constructed from the Schiff base complexes are also characterized by open metal sites. A series of isorecticular chiral MOFs (IRCMOFs) from the chiral Mn-salen-derived dicarboxylate linker and $\left[\mathrm{OZn}_{4}\right]^{6+}$ nodes containing the $\mathrm{Mn}^{3+}$ open metal sites were synthesized in [139]. As a result of the collapse of the framework during the activation process, the $A_{s}$ value of the IRCMOFs was very small, which most likely explains why data on $\mathrm{H}_{2}$ adsorption are lacking [140-146]. The approach in which metal fragments are attached to the organic linkers involves covalent functionalization, followed by metalation and attachment of organometallic complexes to the aromatic components of the linkers. The authors of [147] synthesized the metalated ligand [4,7-bis(4carboxylphenyl)-1,3-dimethylbenzimidazol-2ylidene](pyridyl) $\mathrm{Pd}(\mathrm{II})$ iodide and then integrated it into an IRMOF, which was denoted IRMOF-77 within the $\left[\mathrm{Zn}_{4} \mathrm{O}\left(\mathrm{C}_{28} \mathrm{H}_{21} \mathrm{I}_{2} \mathrm{~N}_{3} \mathrm{O}_{4} \mathrm{Pd}\right)_{3}\right]$ framework. From the $\mathrm{H}_{2}$ bpydc linkers $\left(2,2^{\prime}\right.$-bipyridine-5,5'-dicarboxylic acid), they synthesized the $[\mathrm{Al}(\mathrm{OH})($ bpydc $)]$ framework, 
namely MOF-253, with open 2,2'-bpy coordination sites [148]. As a result of the accessibility of the chelating bpy units, $\mathrm{PdCl}_{2}$ and $\mathrm{Cu}\left(\mathrm{BF}_{4}\right)_{2}$ were impregnated inside the MOF from the solutions of $\mathrm{PdCl}_{2}$ and $\mathrm{Cu}\left(\mathrm{BF}_{4}\right)_{2}$ in acetonitrile. Therefore, MOF-253.xPdCl $2(\mathrm{x}=0.08$; 0.83 ) and MOF-253.0.97 $\mathrm{Cu}\left(\mathrm{BF}_{4}\right)_{2}$ were prepared. In conjunction with the covalent and coordinate covalent postsynthetic modification, the MOF was covalently connected to a chelating group, and then the metalated group. The $\mathrm{Zn}$-pillared paddle wheel MOF with $\mathrm{Zn}_{2}$ (TCPB)(DPG) (TCPB = 1, 2, 4, 5-tetrakis(4-carboxyphenyl)-benzene; $\mathrm{DPG}=$ meso1,2bis(4-pyridyl)-1,2-ethanediol) framework was synthesized and then reacted with the succinic anhydride in [149]. During the chemical reaction between diols in the MOF and succinic anhydride, a product with opened ring and free carboxylic acid groups was obtained. Post-synthetic modification of these carboxylic groups was carried out through the solution impregnation of $\mathrm{CuCl}_{2}$ from its aqueous solution. In [150], the metal-complexed MOF $\left(\mathrm{Zn}_{4} \mathrm{O}\right)_{3}\left(\mathrm{BDC}-\mathrm{C}_{6} \mathrm{H}_{5} \mathrm{~N}_{2} \mathrm{PdCl}_{2}\right)_{3}(\mathrm{BTB})_{4}$ was obtained by chemical reaction between the covalently bound iminopyridine chelate derivative $\left(\mathrm{Zn}_{4} \mathrm{O}\right)_{3}\left(\mathrm{BDC}-\mathrm{C}_{6} \mathrm{H}_{5} \mathrm{~N}_{2}\right)_{3}(\mathrm{BTB})_{4}$ and $\mathrm{PdCl}\left(\mathrm{CH}_{3} \mathrm{CN}\right)_{2}$. In [151], $\mathrm{Zn}{ }_{4} \mathrm{O}\left[(\mathrm{bdc}) \mathrm{Cr}(\mathrm{CO})_{3}\right]_{3}$ was prepared through chemical interaction between the benzenoid phenyl rings of MOF- 5 and the $\mathrm{Cr}(\mathrm{CO})_{3}$ groups. Then, the decarbonylated framework with three open coordination sites per metal was prepared by heat treatment at $473 \mathrm{~K}$. As a result of the aggregation of $\mathrm{Cr}$ atoms, the low-pressure $\mathrm{H}_{2}$ adsorption at $298 \mathrm{~K}$ was lower than the $0.2 \mathrm{H}_{2}$ molecules per formula unit of the MOF. Using the photodecomposition reaction, substitution of a single $\mathrm{CO}$ ligand per metal by the $\mathrm{H}_{2}$ molecule to give $\mathrm{Zn}_{4} \mathrm{O}\left[(\mathrm{bdc}) \mathrm{Cr}(\mathrm{CO})_{2}\left(\mathrm{H}_{2}\right)\right]_{3}$ may be possible. Taking into account the hydrogen binding energy for $\left[\left(\mathrm{C}_{6} \mathrm{H}_{6}\right) \mathrm{Cr}(\mathrm{CO})_{2}\left(\mathrm{H}_{2}\right)\right]$ and $\left[\left(\mathrm{C}_{6} \mathrm{H}_{5} \mathrm{Me}\right) \mathrm{Cr}(\mathrm{CO})_{2}\left(\mathrm{H}_{2}\right)\right]$, a $Q_{s t}$ value of $60-70 \mathrm{~kJ} \cdot \mathrm{mol}^{-1}$ was calculated for $\mathrm{Zn}_{4} \mathrm{O}\left[(\mathrm{bdc}) \mathrm{Cr}(\mathrm{CO})_{2}\left(\mathrm{H}_{2}\right)\right]_{3}$ [152]. MOFs with open metal sites at secondary building units and organic linkers are capable of binding several $\mathrm{H}_{2}$ molecules at a given binding site. This MOF strategy was considered one of the most effective means to increase $\mathrm{H}_{2}$ volumetric capacity in adsorbers of hydrogen gas [153].

\subsubsection{Metal Ions for an Electrostatic Field within the Cavities}

Another approach to increasing the $Q_{s t}$ value is to exchange the cations integrated in the anionic framework with metal ions that have higher affinity to $\mathrm{H}_{2}$ molecules. For example, in the $\mathrm{Mn}_{3}\left[\left(\mathrm{Mn}_{4} \mathrm{Cl}\right)_{3}(\mathrm{BTT})_{8}\right]_{2},(\mathrm{BTT}=1,3,5$-benzenetristetrazolate) framework, $\mathrm{Mn}^{2+}$ ions can be exchanged with $\mathrm{Li}^{+}, \mathrm{Cu}^{+}, \mathrm{Fe}^{2+}, \mathrm{Co}^{2+}, \mathrm{Ni}^{2+}, \mathrm{Cu}^{2+}$, or $\mathrm{Zn}^{2+}$ ions [126] Chemical compositions based on the relative ratio of $\mathrm{Mn}^{+} / \mathrm{Mn}^{2+}$ showed that the total number of extra framework cations is not higher than five. The $Q_{s t}$ values, calculated using a virial fit to the $\mathrm{H}_{2}$ adsorption isotherms at 77 and $87 \mathrm{~K}$, demonstrate a relatively large variation, but they deviate in almost the same region as those for the $\mathrm{Mn}_{3}\left[\left(\mathrm{Mn}_{4} \mathrm{Cl}\right)_{3}(\mathrm{BTT})_{8}\right]_{2}$ framework. The values of hydrogen adsorption capacity measured at $77 \mathrm{~K}$ and 1.2 bar of $\mathrm{H}_{2}$ for the ion-exchange frameworks and the original $\mathrm{Mn}_{3}\left[\left(\mathrm{Mn}_{4} \mathrm{Cl}\right)_{3}(\mathrm{BTT})_{8}\right]_{2}$ were within $2.00-2.29 \mathrm{wt} \%$.

The authors of [154] declared that MOF-5 was partially doped with the $\mathrm{Co}^{2+}$ ions during crystallization in the solvothermal synthesis. Based on inductively coupled plasma (ICP) analysis, the prepared materials were considered to be Co8-MOF- 5 with the composition of the $\mathrm{Zn}_{3 \cdot 68} \mathrm{Co}_{0.32} \mathrm{O}(\mathrm{BDC})_{3}(\mathrm{DEF})_{0.75}$ (DEF = diethylformamide) framework containing $8 \%$ $\mathrm{Co}$ and $92 \% \mathrm{Zn}$, and Co21-MOF-5 with the composition of $\mathrm{Zn}_{3 \cdot 16} \mathrm{Co}_{0} \cdot 84 \mathrm{O}(\mathrm{BDC})_{3}(\mathrm{DEF})_{0 \cdot 47}$ containing $21 \% \mathrm{Co}$ and $79 \% \mathrm{Zn}$. The ICP results showed that for these Co-MOF-5 materials, the substitution of more than one $\mathrm{Co}^{2+}$ ion in $\left[\mathrm{OZn}_{4}\right]^{6+}$ nodes was difficult. In addition, the XRD results confirmed that the crystal structure of both undoped and Co-doped MOF- 5 was identical. In practice, during the removal of solvent, the coordination geometry around $\mathrm{Co}^{2+}$ changed from octahedral to tetrahedral due to the loss of two DEF molecules. The values of the hydrogen adsorption capacity at $77 \mathrm{~K}$ and 10 bar of $\mathrm{H}_{2}$ were in the order of Co21-MOF-5 > Co8-MOF-5 > MOF-5. A small increase in the $Q_{s t}$ value was experimentally found for Co21-MOF-5 ( $\sim 7 \mathrm{~kJ} \cdot \mathrm{mol}^{-1}$ vs. $5.5 \mathrm{~kJ} \cdot \mathrm{mol}^{-1}$ for MOF-5). The results obtained suggested that the $\mathrm{Co}^{2+}$ ions incorporated into MOF-5 played an important role in the 
hydrogen adsorption process, even being incorporated into the "protected" metal sites that were less accessible to $\mathrm{H}_{2}$ molecules.

Recently, a theoretical assumption of a "regional dynamic electric field effect" was proposed in [155] to explain a selective adsorption of $\mathrm{CO}_{2}$ over $\mathrm{N}_{2}, \mathrm{O}_{2}$, and $\mathrm{CH}_{4}$ in the $[\mathrm{Co}($ tipb $)(\mathrm{adc})](\mathrm{DMF})_{3}\left(\mathrm{H}_{2} \mathrm{O}\right)_{1.5} \quad($ tipb $\quad=\quad 1,3,5$-tris $(\mathrm{p}$-imidazolylphenyl)benzene; adc $=9,10$-anthracenedicarboxylate) framework. It was concluded that regional dynamic electric fields do exist in MOFs, and their polarizability and quadruple moment might be considered the crucial factors for gas adsorption. According to the proposed effect, the gas adsorption capacity and selectivity can be enhanced by intensifying the electric field and potential gradient of the effective adsorption space in the MOF through structure modification. This cobalt-based MOF with tipb and adc linkers is a good example of making a connection between peculiarities in the crystal structure, the level of $\mathrm{H}_{2}$ adsorption, and the $Q_{s t}$ value. In practice, the metal doped MOFs demonstrated a positive impact on hydrogen adsorption at $298 \mathrm{~K}$, which might be explained by a higher interaction between metal ions and $\mathrm{H}_{2}$ molecules.

\subsection{Catalytic Effect and Pore Design}

Due to their high affinity to hydrogen, the platinum group metals were the first catalysts used in various hydrogenation reactions and processes related to $\mathrm{H}_{2}$ molecules. Subsequently, a hydrogen spill-over effect was defined as dissociative chemical sorption (i.e., $\mathrm{H}_{2} \rightarrow 2 \mathrm{H}$ ) on the catalyst surface and the later migration of $\mathrm{H}$ atoms onto the surface of support. The catalytic effect was also used for MOFs in an attempt to accelerate the hydrogen adsorption process. In addition, the morphology of pores and their extra functionalization were taken into consideration. In the case of microporous MOFs, the morphology of the pores represents their main characteristics, including the geometrical shape (pore width and pore volume) and roughness of the pore walls. A small pore diameter was found to be an important factor for the achievement of a high value of hydrogen adsorption capacity at room temperature.

\subsubsection{Incorporated Metal Nanoparticles}

Recently, the idea of the hydrogen spillover effect has been transferred to MOFs, and the introduction of several types of metal nanoparticles (NPs) to MOFs has been considered (Figure 10) [156-159]. The simplest method involves preparing a coating made of the NP metal on the MOF surface, but without completely wrapping the MOF in a metal thin film (Figure 10a). Using a solid grinding approach, Au NPs were attached to the surface of the well-known MOF examples, including MOF-5 [160]. The solution impregnation method was reported to be a convenient tool for preparing metal NPs infiltrated inside MOFs (Figure 10b). Typically, the metal precursor solution fills the MOF pores by capillary force, and the chemical reduction (e.g., with $\mathrm{H}_{2}, \mathrm{NaBH}_{4}$ ) then produces the NPs settled in the body of the MOF. This method was successfully used to prepare mono- and bimetallic NPs inside MOFs (e.g., Pt NPs [161-164] and Pt/Ni NPs [165]). In addition, the chemical vapor deposition (CVD) technique was found to be advantageous in the deposition of metal nanoparticles in MOFs because, during the CVD vapor phase, the precursor is loaded in MOFs, and the precursor is then decomposed or reduced to obtain nanoparticles inside the MOF pores. Using the CVD method, MOF- 5 was first infiltrated with $\mathrm{Cu}, \mathrm{Pd}$, and $\mathrm{Au}$ NPs in 2005 [166]. Ten years later, a new method of NP incorporation inside MOFs was developed based on encapsulation (that is, not infiltration) of the pre-synthesized NPs by growing MOF around them (Figure 10c) $[167,168]$. It is very important that the MOF cavities remain unharmed, and this kind of material can provide a synergistic function that is derived from both NPs and MOFs [169]. In this case, the metal NPs are completely enclosed in the so-called "metal@MOF" [170]. The interfacial region between MOFs and metal NPs plays an important catalytic role in the improvement of gas adsorption. In addition, because of a special core/shell design, MOFs can act as a partition between the NPs to prevent their sintering during the reaction, resulting in high durability. 

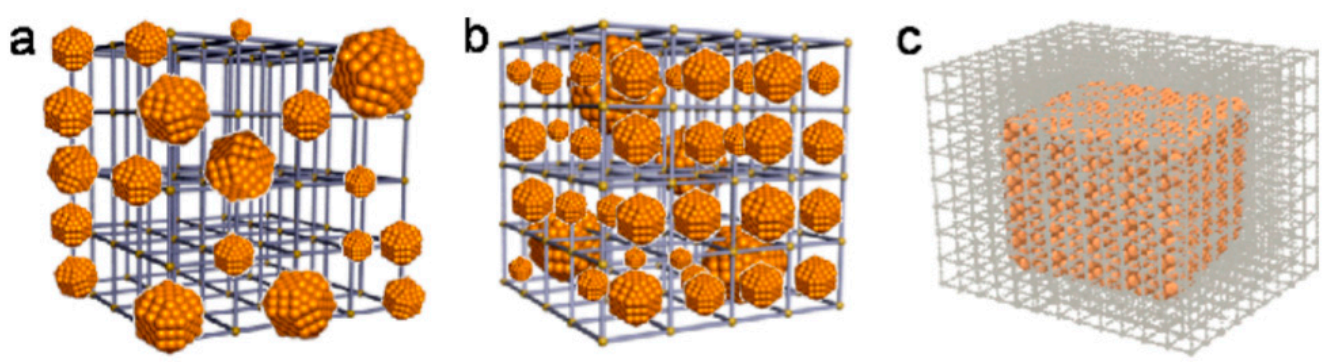

Figure 10. Representative methods of preparation of composites consisting of metal nanoparticles and MOF. (a) A solid grinding method. (b) The solution infiltration. (c) An encapsulation of presynthesized nanoparticles by growing the MOF around them. Reprinted with permission from [158]. Copyright ( 2016, American Chemical Society. All rights reserved.

Palladium was among the first examples of metal NPs inside MOFs. For example, Pd NPs (with an average size of $2.5 \mathrm{~nm}$ ) were successfully infiltrated in MIL-100(Al) with a high metal content (10 wt\%) without degradation of MOF [171]. As a result of Pd impregnation, the reduction in the $n_{\sigma}$ value at $77 \mathrm{~K}$ and 40 bar of $\mathrm{H}_{2}$ was directly related to the decrease in the $A_{s}$ and $V_{a}$ values (from 380 to $1200 \mathrm{~m}^{2} \cdot \mathrm{g}^{-1}$, and from 0.33 to $0.65 \mathrm{~cm}^{3} \cdot \mathrm{g}^{-1}$, respectively), whereas at $298 \mathrm{~K}$, the $n_{\sigma}$ value increased, most probably because of the $\mathrm{Pd}$ hydride formation. Formation of $\mathrm{PdH}_{0.6}$ was experimentally confirmed for the Pd NPs incorporated in MIL-100(Al), although the spill-over effect was also considered. As a result of the spill-over effect, faster kinetics was experimentally observed for $\mathrm{Pd}$ NPs encapsulated in HKUST-1 (Cu(II) 1,3,5-benzenetricarboxylate) [169]. A lower field shift in solid state ${ }^{2} \mathrm{H}$ NMR suggested that relatively large amounts of hydrogen were located in the Pd lattice of Pd@HKUST-1 than those of the pure Pd NPs. Additionally, XPS measurements showed that Pd 3d binding energies of Pd@HKUST-1 were shifted to higher energy, suggesting that $\mathrm{Pd}$ was in a partial oxidization state. In contrast, the $\mathrm{Cu}$ 2p binding energies of Pd@HKUST-1 were shifted to lower energy, suggesting a partial reduction in $\mathrm{Cu}^{2+}$. Based on XPS data, it was concluded that the electrons in the Pd NPs were slightly transferred to HKUST-1, and this electron transfer may be accountable for the increased number of holes in the $4 \mathrm{~d}$ band of Pd NPs encapsulated in HKUST-1, resulting in a higher amount of $\mathrm{H}_{2}$ adsorption. Pd NPs with a size of $1 \mathrm{~nm}$ were successfully infiltrated inside MIL-101 up to $20 \mathrm{wt} \%$ [172]. Experimentally, it was confirmed that during $\mathrm{H}_{2}$ absorption Pd NPs with a size of 2-3 nm formed a hydride phase (as in the case of bulk Pd), whereas Pd NPs with a size of $1 \mathrm{~nm}$ created solid solutions under ambient conditions. Additionally, it was concluded that because of the size effect, a decrease in the critical temperature of the two-phase region below room temperature occurred, and the $E_{a}$ value of $\mathrm{H}_{2}$ desorption for Pd NPs was lower than that of bulk Pd. The authors of [173] attempted to introduce Pd NPs inside the [Al(OH)BPDC] (BPDC $=4$, 4'-biphenyldicarboxylic acid) framework, which is well known as DUT-5, using a solution impregnation procedure, as in [171]. The structure of DUT- 5 was partially destroyed because of acid treatment during Pd NP infiltration, and this was the main reason for lower $\mathrm{H}_{2}$ adsorption compared with pristine DUT-5. Nevertheless, the higher content of Pd NPs (from $1 \%$ to $5 \%$ ) promoted enhanced $\mathrm{H}_{2}$ adsorption at $298 \mathrm{~K}$ and 50 bar of $\mathrm{H}_{2}$, which was explained by the spill-over effect. Using theoretical predictions, the authors of [174] infiltrated Pd NPs in the pores of Br-UiO-66 and confirmed the strong host-guest interactions that keep Pd NP inside MOF. It was concluded that only monofunctionalized linkers (e.g., 2-bromoterephthalate or 2-aminoterephthalate) allowed intercalation of $\mathrm{Pd}$ NPs in the MOF pores, which was in contrast to the unfunctionalized (terephthalate) or biofunctionalized (2,5-dichloroterephthalate and 2,5-dihydroxylterephthalate) linkers. Additionally, it was summarized that the Pd NPs were maintained in the pores of MOFs with different functionalities, and accordingly had different degrees of interaction with the frameworks. This approach was proposed as a means of altering the catalytic activity of the metal NPs. 
Platinum is another attractive example of the incorporation of metal NPs in MOFs. In 2010, two independent research groups studied MOF-5 doped with Pt NPs [175,176]. They prepared composites as physical mixtures and connected MOF- 5 with Pt catalysts ( 5 and $10 \mathrm{wt} \%$ ) via carbon bridges. The authors experimentally found a correlation between hydrogen adsorption and BET surface area, suggesting a typical physisorption process [175] and that the structure of the composites was similar to that of pristine MOF-5 [176]. The measured $\mathrm{H}_{2}$ adsorption of the carbon-bridged MOF- 5 with Pt NPs was even less than that of $\mathrm{Pt}$ NPs on activated carbon [175]. A decrease in $\mathrm{H}_{2}$ uptake for the composites compared to pure MOF-5 was found in [176] and attributed to degradation of the textural properties. Moreover, no hydrogen spillover effects were found in $[175,176]$. On the contrary, due to the incorporation of Pt NPs in IRMOF-8 [177] and MOF-177 [178], an increase in $\mathrm{H}_{2}$ adsorption was experimentally observed. For Pt-modified IRMOF-8 prepared by CVD, the dependence of hydrogen adsorption capacity on the size of Pt NPs was indicated as Pt/IRMOF-8-1 > Pt/IRMOF-8-2 > Pt/IRMOF-8-3, where the incorporated Pt NPs had sizes of 2.2, 3.9, and $9.1 \mathrm{~nm}$, respectively. This indicates that, depending on the pore's size in MOFs, surface decoration or bulk infiltration with NPs may be possible; therefore, the geometry of both NPs and MOFs should be taken into account. Additionally, it was concluded that the Pt NPs embedded in MOFs may adsorb and absorb $\mathrm{H}$ atoms to hydrogenate $\mathrm{Pt}$ to a stable metal hydride. This happened, for example, for Pt@MOF-177 [178]. The encapsulated Pt NPs in MOF-177 showed $\mathrm{H}_{2}$ adsorption of $2.5 \mathrm{wt} \%$ at $298 \mathrm{~K}$ and 144 bar of $\mathrm{H}_{2}$ in the first adsorption cycle, but only $0.5 \mathrm{wt} \%$ in the second cycle, which was similar to the value of pure MOF-177. Therefore, to avoid direct hydrogenation of the metal NPs incorporated in MOFs, the platinum group metals should be changed to transition metals to ensure they do not react readily with atomic hydrogen.

Scandium and titanium may be considered as promising candidates for their incorporation as NPs in MOFs. In the theoretical work [179], the effect of these light transition metals on the hydrogen adsorption in MOF- 5 was calculated using the ab initio density functional theory (DFT). The calculations predicted that Ti atoms may undergo clustering (Figure 11), whereas Sc atoms preferred the full metal decoration of MOF-5. Both Sc- and Ti-decorated MOF-5 may adsorb the $5 \mathrm{H}_{2}$ molecules per metal atom, resulting in a theoretical hydrogen adsorption capacity of 5.81 and $5.72 \mathrm{wt} \%$, respectively. The calculated $Q_{s t}$ value was predicted within the range of $20-40 \mathrm{~kJ} \cdot \mathrm{mol}^{-1}$ and additional improvement in the interaction energy between the metals and MOF- 5 may be achieved with boron substitution.

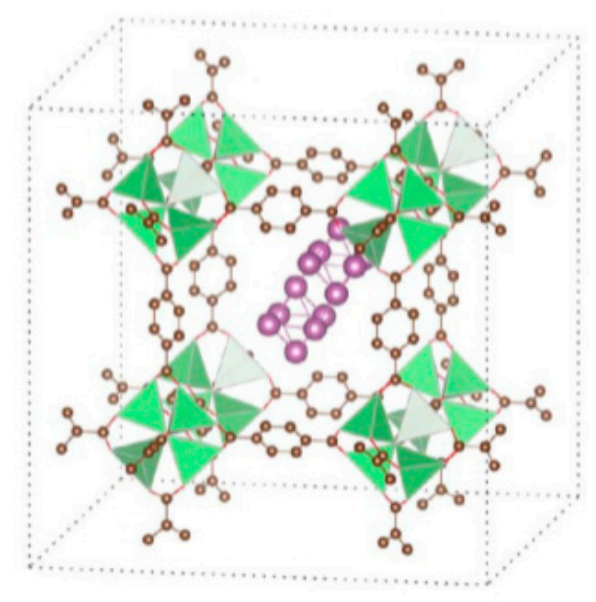

(a)

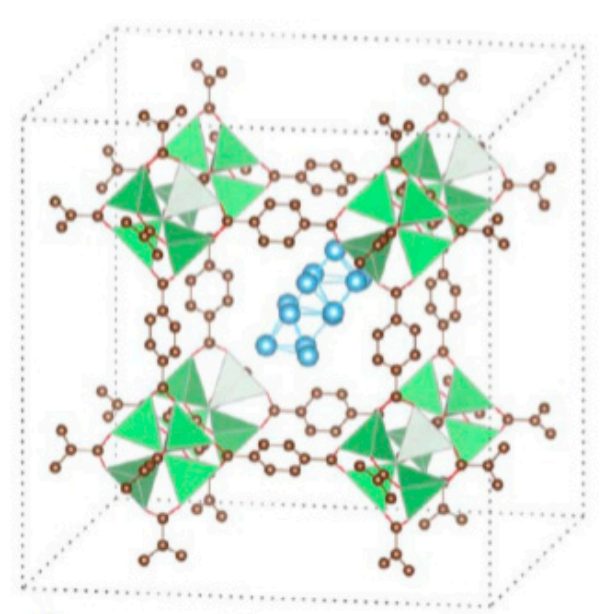

(b)

Figure 11. Optimized geometry of MOF-5 in which a cluster of 12 metal atoms of Sc (a) or Ti (b) is relaxed inside the pore. Reprinted with permission from [179]. Copyright (c) 2012, American Chemical Society. All rights reserved. 
Successful preparation of Ni NPs in Ni-MOF-74 was carried out with a partial thermal decomposition of the same MOF [180]. The $\mathrm{Ni}_{2}$ (dhtp) $\left(\mathrm{H}_{4} \mathrm{dhtp}=2,5\right.$-dihydroxyterephthalic acid) framework is characterized by pores with a size of $\sim 11 \AA$ and integrated from the $\mathrm{Ni}^{2+}$ nodes, which can be chemically reduced by organic linkers (hydroqinone). In this thermal method, the size of the intercalated Ni NPs can be altered with temperature values. Surface decoration with the NiNPs was made for MIL-100, and the resulting material showed a high catalytic activity for hydrogen evolution reaction (HER) [181]. Then, the NiMo alloy was introduced into MIL-101 and the prepared NiMo@MIL-101 demonstrated greater HER catalytic activity than that of Ni@MIL-101 [182]. Ni NP intercalation in MOF-5 was carried out in [183] and the synthesized Ni@MOF-5 was tested as a catalyst in the production of $\mathrm{H}_{2}$ from water splitting under visible light irradiation. The Ni-modified MOFs were widely investigated in terms of their catalytic and optical properties [184] but were not considered to be an effective porous material for $\mathrm{H}_{2}$ adsorption. Development of the preparation methods to incorporate metal NPs in MOFs began several years ago, but the isosteric enthalpy of their hydrogen adsorption and hydrogen adsorption capacity has not been fully examined. In addition, the origin of the enhanced $\mathrm{H}_{2}$ adsorption, and the mechanism of interactions between metal NPs and MOFs, remain unclear.

\subsubsection{Morphology of Pores and Their Functionalization}

The effect of the pore size may be explained by the fact that the small diameter of pores enables energy potentials to overlap between the opposing walls, resulting in higher interaction energy with $\mathrm{H}_{2}$ molecules [185]. For example, MOFs of $\mathrm{M}(\mathrm{HBTC})$ (4,4'-bpy) $3 \mathrm{DMF}\left(\mathrm{M}=\mathrm{Ni}\right.$, Co; HBTC = 1,3,5-benzenetricarboxylic acid; 4,4'-bipy $=4,4^{\prime}$ bipyridine; $\mathrm{DMF}=\mathrm{N}, \mathrm{N}^{\prime}$-dimethylformamide) showed $\mathrm{H}_{2}$ adsorption of 3.42 and $2.05 \mathrm{wt} \%$ at $77 \mathrm{~K}$ and 1 bar of $\mathrm{H}_{2}$, and 1.20 and $0.96 \mathrm{wt} \%$ at $298 \mathrm{~K}$ and 70 bar of $\mathrm{H}_{2}$, respectively [186]. The $A_{s}$ values measured by the BET method were 1590 and $887 \mathrm{~m}^{2} \cdot \mathrm{g}^{-1}$, respectively, but it was noted that these two frameworks had nonlinear rectangular channels with an average size of $7 \times 6 \AA$. Another $\left[\mathrm{Co}_{3}(\mathrm{NDC})_{3}(\right.$ dabco $\left.)\right]$ (dabco = 1,4-diazabicyclo[2.2.2]octane $)$ framework with a primitive cubic structure demonstrated $0.89 \mathrm{wt} \%$ of $\mathrm{H}_{2}$ at $298 \mathrm{~K}$ and $P\left(\mathrm{H}_{2}\right)=17.2$ bar, which was explained by both the $A_{s}$ value $\left(1502 \mathrm{~m}^{2} \cdot \mathrm{g}^{-1}\right)$ and the average pore diameter $(4.5 \AA)$ [187]. The four-fold interpenetrating networks based on the $\left[\mathrm{OZn}_{4}\right]^{6+}$ nodes with 3D channels $(<5 \AA)$ might also be considered. These examples indicate that, even with a small $A_{s}$ value, hydrogen adsorption can be significant and, most importantly, controlled by pore size (5-7 $\AA$ ).

It is clear that the morphology of pores, in addition to the chemical environment of all of the pore walls, can be adjusted with functionalization of the internal surface of MOFs. The value of this functionalization has also been considered to be a possible impact on $\mathrm{H}_{2}$ adsorption. The authors of [188] attempted to change the pore morphology of MOFs to improve the $Q_{s t}$ value and hydrogen adsorption capacity. They reacted IRMOF-3, DMOF-1-NH $\mathrm{NH}_{2}$, and UMCM-1-NH $\mathrm{NH}_{2}$ with anhydrides or isocyanates to obtain IRMOF3-AM5, IRMOF-3-AMPh, IRMOF-3-URPh, DMOF-1-AMPh, and UMCM-1-AMPh with pore functionalization by amide groups (Figure 12). It was experimentally confirmed that the post-synthetic modification resulted in higher $\mathrm{H}_{2}$ adsorption, especially when pore functionalization was undertaken with phenyl ring substituents. This supports the suggested role of aromatic rings on hydrogen adsorption presented in Section 4.1.1.

The authors of [189] constructed functional porous MOFs via the reaction of $\mathrm{Ni}^{2+}$ ions with 2,4,6-tri(4-pyridinyl)-1,3,5-triazine (tpt) and $o$-phthalic acid as a co-ligand. It was concluded that the decoration of the pores' surface and tuning of adsorption properties could be achieved by introducing different functional groups on the $o$-phthalic acid ligand; therefore, a new class of TKL frameworks (TKL = Tianjin Key Lab of Metal and Molecule Based Materials) with different functionalized $\left(-\mathrm{NH}_{2},-\mathrm{NO}_{2}\right.$, and $\left.-\mathrm{F}\right) o$-phthalic acid was studied. It was determined experimentally that all of the fluorinated MOFs with different numbers and positions of substituted F-atoms demonstrated high values of $A_{s}$ and $\mathrm{H}_{2}$ adsorption. At 65 bar of $\mathrm{H}_{2}$ and $77 \mathrm{~K}$, hydrogen adsorption for TKL-106 and 
TKL-107 was estimated to be 6.24 and $4.00 \mathrm{wt} \%$, respectively. Due to pore functionalization, greater interaction between $\mathrm{H}_{2}$ molecules and the fluorinated MOFs was explained by the micropore diameter (approximately $6.0 \AA$ ), which is very close to the approximate size of two $\mathrm{H}_{2}$ molecules $(2 \times 2.8 \AA)$.

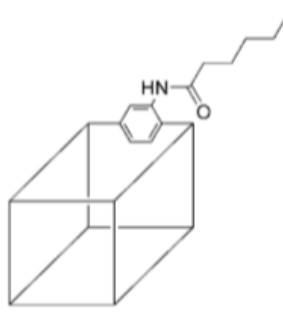

IRMOF-3-AM5

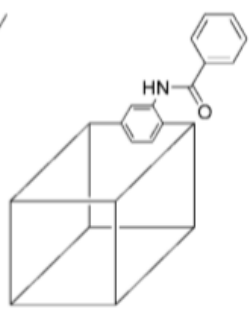

IRMOF-3-AMPh

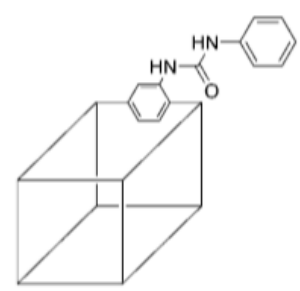

IRMOF-3-URPh

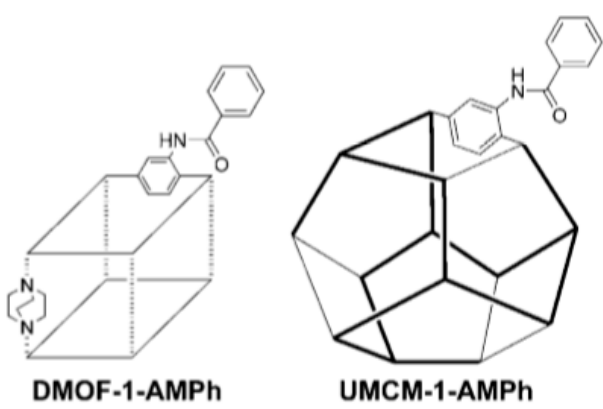

Figure 12. Schematic representation of pore functionalization by amide groups in IRMOF-3-AM5, IRMOF-3-AMPh, IRMOF-3-URPh, DMOF-1-AMPh, and UMCM-1-AMPh. Reprinted with permission from [188]. Copyright (C 2010, Wiley-VCH Verlag GmbH\&Co. KGaA, Weinheim. All rights reserved.

In the experimental work [190], the effect of solvent used in MOF-5 preparation on pore morphology was studied. Narrow slit-like pores with internal irregular voids were observed in the synthesized MOF-5 with coexisting micro-, meso-, and macropores. For meso- and macroporous regions, the values of hydrogen $Q_{s t}$ were calculated as 3.68 and $12.45 \mathrm{~kJ} \cdot \mathrm{mol}^{-1}$, respectively. The higher value was explained by the presence of a residual solvent in macropores, which increased interactions between $\mathrm{H}_{2}$ molecules and pore walls.

\section{Prospective Views and Outlooks}

MOFs are unique chemical compounds that can be used in numerous scientific applications, including hydrogen adsorption; however, adapting a pure MOF to the DoE target to be used as an effective hydrogen storage material remains a significant challenge. The factors of surface area and pore volume remain the most critical issue, because at $298 \mathrm{~K}$, the $n_{a}$ value correlates mainly with the $V_{a}$ value at low $P\left(\mathrm{H}_{2}\right)$ and the $A_{s}$ value at high $P\left(\mathrm{H}_{2}\right)$. Organic linkers have a direct influence on the pore morphology, and therefore, on the surface area of MOFs, their length, chemical composition, and flexibility may explain the catenation and sponge-like dynamic mechanism in MOFs. These effects may change the hydrogen adsorption in pure MOFs, but their absolute quantity of adsorbed hydrogen does not meet the DoE requirements at $298 \mathrm{~K}$, or at 100 bar of $\mathrm{H}_{2}$. The value of $Q_{s t}$ may be considered to be a reasonable indicator of the applicability of pure MOFs as a hydrogen storage material. At $298 \mathrm{~K}$, a tendency exists to form a proportional relationship between the $Q_{s t}$ and the $n_{\sigma}$ values, and using the approach of open metal sites or an electrostatic field, isosteric enthalpy of hydrogen adsorption increases slightly in pure MOFs. Numerous calculations suggest with values of $Q_{s t}$ within the range of $15-25 \mathrm{~kJ} \cdot \mathrm{mol}^{-1}$, with a $V_{a}$ value of $\sim 2.5 \mathrm{~cm}^{3} \cdot \mathrm{g}^{-1}$ and porosity of $\sim 85 \%$, would be desirable for an MOF as a successful candidate for hydrogen storage with $9 \mathrm{wt} \%$ of $\mathrm{H}_{2}$.

Nanoscaffolding materials based on MOFs, sometimes generalized to "hybrid" or "functional" composites, may combine properties of their components. In practice, isos- 
teric enthalpy of hydrogen adsorption and hydrogen adsorption capacity has not been fully examined for this kind of material, and is not reproducible for the same examples. The main reasons for these discrepancies may lie in the morphology of pores and their functionalization, which is highly sensitive to the synthesis procedure and post-synthetic modification of MOFs. Another approach to nanoscaffolding materials based on MOFs may be nanoconfinement of metal hydrides inside the frameworks, in which MOFs are considered to be nanoscaffolds rather than $\mathrm{H}_{2}$ sorbents. The main advantages of nanoconfined hydrides relate to their faster kinetics, higher reversibility, and the change in the mechanism of hydrogen interaction. The additional weight of nanoscaffolds leads to lower gravimetric hydrogen sorption capacity in the composite material. Recently, MOFs characterized by the morphology of their pores and functionalization were considered to be suitable microporous scaffolds. For example, the Ti-modified $\mathrm{NaAlH}_{4}$ infiltrated in MOF-74(Mg) was successfully synthesized by melt infiltration, achieving loadings up to $21 \mathrm{wt} \%$ [191]. MOF-74(Mg) characterized by pores with a diameter of $12 \AA$ and lined with $\mathrm{Mg}$ atoms have open coordination sites, which were considered to be sites for $\mathrm{TiCl}_{4}$ stabilization. In practice, nanoconfinement of $\mathrm{NaAlH}_{4}$ has indicated advantages with respect to the bulk analogue (Table 4) [191]. The first, typical decomposition pathway for bulk $\mathrm{NaAlH}_{4}$ was simplified by avoiding the stable $\mathrm{Na}_{3} \mathrm{AlH}_{6}$ intermediate production. Secondly, kinetics of decomposition for nanoconfined $\mathrm{NaAlH}_{4}$ was higher, as confirmed by lowered values of the $\mathrm{T}_{\mathrm{dec}}\left(\mathrm{NaAlH}_{4}\right)$ and decreased values of activation energy $\left(E_{a}\right)$. Titanium modification considerably increased the reversibility of the $\mathrm{NaAlH}_{4}$ decomposition-formation. These obtained results were explained by chemical and structural features of MOF-74(Mg), which was used as an effective nanoscaffold for $\mathrm{NaAlH}_{4}$. Micropores of MOF-74(Mg) allow $\mathrm{NaAlH}_{4}$ to be in close contact with the pore walls; hence, the chemical environment of all of the pore walls can stabilize the final decomposition products (including $\mathrm{H}_{2}$ molecules), avoiding their diffusion and agglomeration.

Table 4. Hydrogen adsorption capacity and activation energy of decomposition for nanoconfined and bulk $\mathrm{NaAlH}_{4}$. Hydrogen adsorption capacity was measured at $433 \mathrm{~K}$ and 105 bar of $\mathrm{H}_{2}$, and the mass of MOF-74(Mg) was excluded from the determination of the hydrogen amount. Reprinted with permission from [191]. Copyright (C) 2012, American Chemical Society. All rights reserved.

\begin{tabular}{|c|c|c|c|}
\hline $\mathrm{NaAlH}_{4}$ & Amount of $\mathrm{Ti}, \mathrm{mol} \%$ & $\begin{array}{c}E_{a \prime} \\
\mathrm{kJ} \cdot \mathrm{mol}^{-1}\end{array}$ & $\begin{array}{c}\mathrm{H}_{2} \text { Adsorption, } \\
\mathrm{wt} \%\end{array}$ \\
\hline Bulk & 0 & 118.1 & 5.12 \\
\hline Bulk & 2 & 79.5 & 4.25 \\
\hline $\begin{array}{l}\text { Infiltrated in } \\
\text { MOF-74(Mg) }\end{array}$ & 3 & 57.4 & 4.20 \\
\hline
\end{tabular}

In another example, highly reactive gaseous $\mathrm{Ti}\left(\mathrm{BH}_{4}\right)_{3}$ molecules at $298 \mathrm{~K}$ were infiltrated into UiO-66 [192]. The nanoconfined hydride was stabilized in the porous MOF up to $350 \mathrm{~K}$ under vacuum and reached approximately double gas density. After $\operatorname{Ti}\left(\mathrm{BH}_{4}\right)_{3}$ infiltration, the value of UiO-66 obtained by the BET method decreased from 1200 to $770 \mathrm{~m}^{2} \cdot \mathrm{g}^{-1}$. The nanoconfined $\mathrm{Ti}\left(\mathrm{BH}_{4}\right)_{3}$ demonstrated another mechanism of decomposition, including the production of pentaborane rather than diborane in the case of pure $\mathrm{Ti}\left(\mathrm{BH}_{4}\right)_{3}$. These experimental results encourage the development of other examples of nanoconfinement, including solid hydrides with a high hydrogen content and stable MOFs with pore characteristics suitable for effective nanoscaffolding.

To optimize the hydrogen adsorption process, data are required regarding the physicochemical characteristics of MOFs to better understand their interaction with $\mathrm{H}_{2}$ molecules. To obtain such important information, vibrational spectroscopy plays a crucial role and is often notable in many cases. At present, IR and Raman spectroscopies are considered to be powerful tools for initial characterization of MOFs and their composites, including in situ measurements under hydrogen adsorption, in addition to their combinations with 
other techniques to study crystal structure and morphology, and physical and chemical properties of MOFs [193].

\section{Conclusions}

Hydrogen sorption is a complex physical and chemical process, which includes both adsorption at the surface and absorption into the bulk. Different hydrogen storage material MOFs may represent an opportunity to study the molecular hydrogen interaction with microporous crystalline materials made of metal nodes and organic linkers. The main benefit of MOFs relates to their reversible and high-rate hydrogen adsorption process, whereas their biggest disadvantage is their operation at very low temperatures. Using the factors of surface area, pore volume, and isosteric enthalpy of hydrogen adsorption, storage of hydrogen gas in MOFs may be increased. The catalytic effect and pore design are anticipated to be additional influences on hydrogen adsorption because of the incorporated catalyst inside the MOFs and their pore functionalization. Nanoscaffolding materials, in which MOFs are considered to be nanoscaffolds, rather than $\mathrm{H}_{2}$ adsorbents, may be considered to be a suitable nanotechnology to achieve DoE conditions when this approach can be used to reduce the gravimetric hydrogen storage capacity.

Author Contributions: V.Z. and I.S. wrote and reviewed the article. All authors have read and agreed to the published version of the manuscript.

Funding: This work was supported by the Scientific Grant Agency VEGA Project No. 1/0865/21. The author V.Z. thanks the Ministry of Education, Science, Research, and Sport of the Slovak Republic and the Accreditation Commission for the financial support of the TRIANGEL team within the frame of the scheme, "Top Research Teams in Slovakia". Financial support was also provided by the Slovak Academic Information Agency (SAIA) within the National Scholarship Program of the Slovak Republic in 2019/2020 for the author I.S., as the scholarship holder, under the supervision of V.Z.

Conflicts of Interest: The authors declare no conflict of interest. The funders had no role in the design of the study; in the collection, analyses, or interpretation of data; in the writing of the manuscript; or in the decision to publish the results.

\section{References}

1. Communication from the Commission to the European Parliament, the European Council, the Council, the European Economic and Social Committee and the Committee of the Regions. The European Green Deal, COM/2019/640 final. Available online: https:/ / eur-lex.europa.eu/legal-content/EN/ALL/?uri=COM:2019:640:FIN (accessed on 16 April 2021).

2. A European Green Deal. Striving to Be the First Climate-Neutral Continent. Available online: https://ec.europa.eu/info/ strategy/priorities-2019-2024/european-green-deal (accessed on 16 April 2021).

3. Communication from the Commission to the European Parliament, the European Council, the Council, the European Economic and Social Committee and the Committee of the Regions. A Hydrogen Strategy for a Climate-Neutral Europe, COM/2020/301 Final. Available online: https:/ / ec.europa.eu/energy/sites/ener/files/hydrogen_strategy.pdf (accessed on 16 April 2021).

4. Hydrogen Roadmap Europe, A Sustainable Pathway for the European energy Transition. Available online: https://www.fch. europa.eu/sites/default/files/Hydrogen\%20Roadmap\%20Europe_Report.pdf (accessed on 16 April 2021).

5. Heynes, G. Tokyo Olympic Torch to be powered by hydrogen, In H2 View. 26 March 2021. Available online: https:/ /www.h2 -view.com/story/tokyo-olympic-torch-to-be-powered-by-hydrogen/ (accessed on 16 April 2021).

6. Klein, A. Japan wants to use the Olympic games to promote hydrogen to the world. In NewScientist. 26 May 2021. Available online: https:/ / www.newscientist.com/article/mg25033362-100-japan-wants-to-use-the-olympic-games-to-promote-hydrogento-the-world/ (accessed on 27 May 2021).

7. Hydrogen Energy Storage Markets 2019-Global Forecast to 2024, Research and Markets, 22 October 2019. Available online: https:/ / www.researchandmarkets.com/reports /4849112/hydrogen-energy-storage-market-by-state-liquid?utm_source=CI\& utm_medium=PressRelease\&utm_code=sf8vnn\&utm_campaign=1310239+-+Hydrogen+Energy+Storage+Markets $+2019+-$ +Global+Forecast+to+2024\&utm_exec=chdo54prd (accessed on 16 April 2021).

8. Materials-Based Hydrogen Storage, Office of Energy Efficiency \& Renewable Energy, U.S. Department of Energy. Available online: https: / / www.energy.gov / eere/fuelcells/materials-based-hydrogen-storage (accessed on 16 April 2021).

9. Semelsberger, T.A. Fuels-Hydrogen storage. Chemical carriers. In Encyclopedia of Electrochemical Power Sources; Elsevier: Oxford, UK, 2009; pp. 504-518.

10. Sakintuna, B.; Lamari-Darkrim, F.; Hirscher, M. Metal hydride materials for solid hydrogen storage: A review. Int. J. Hydrogen Energy 2007, 32, 1121-1140. [CrossRef] 
11. Graetz, J. New approaches to hydrogen storage. Chem. Soc. Rev. 2009, 38, 73-82. [CrossRef]

12. Li, H.; Yan, Y.; Orimo, S.; Züttel, A.; Jensen, C.M. Recent progress in metal borohydrides for hydrogen storage. Energies 2011, 4, 185-214. [CrossRef]

13. Paskevicius, M.; Jepsen, L.H.; Schouwink, P.; Černy, R.; Ravnsbæk, D.B.; Filinchuk, Y.; Dornheim, M.; Besenbacher, F.; Jensen, T.R. Metal borohydrides and derivatives-Synthesis, structure and properties. Chem. Soc. Rev. 2017, 46, 1565-1634. [CrossRef]

14. Jain, A.; Agarwal, S.; Ichikawa, T. Catalytic Tuning of Sorption Kinetics of Lightweight Hydrides: A Review of the Materials and Mechanism. Catalysts 2018, 8, 651-687. [CrossRef]

15. Milanese, C.; Jensen, T.R.; Hauback, B.C.; Pistidda, C.; Dornheim, M.; Yange, H.; Lombardo, L.; Züttel, A.; Filinchuk, Y.; Ngene, P.; et al. Complex hydrides for energy storage. Int. J. Hydrogen Energy 2019, 44, 7860-7874. [CrossRef]

16. Lai, Q.; Sun, Y.; Wang, T.; Modi, P.; Cazorla, C.; Demirci, U.B.; Ares Fernandez, J.R.; Leardini, F.; Aguey-Zinsou, K.F. How to design hydrogen storage materials? Fundamentals, synthesis, and storage tanks. Adv. Sustain. Syst. 2019, 3, 1900043. [CrossRef]

17. Hirscher, M.; Yartys, V.A.; Baricco, M.; von Colbe, J.B.; Blanchard, D.; Bowman, R.C., Jr.; Broom, D.P.; Buckley, C.E.; Chang, F.; Chen, P.; et al. Materials for hydrogen-based energy storage-Past, recent progress and future outlook. J. Alloys Comp. 2020, 827, 153548-153587. [CrossRef]

18. El Kharbachi, A.; Dematteis, E.M.; Shinzato, K.; Stevenson, S.C.; Bannenberg, L.J.; Heere, M.; Zlotea, C.; Szilágyi, P.Á.; Bonnet, J.-P.; Grochala, W.; et al. Metal hydrides and related materials. Energy carriers for novel hydrogen and electrochemical storage. J. Phys. Chem. C 2020, 124, 7599-7607. [CrossRef]

19. Dagani, R. The bio side of organometallics. Chem. Eng. News 2002, 80, 23-29. [CrossRef]

20. Froudakis, G.E. Hydrogen interaction with carbon nanotubes: A review of ab initio studies. J. Phys. Cond. Matter 2002, 14, R453. [CrossRef]

21. Germain, J.; Hradil, J.; Frechet, J.M.J.; Svec, F. High Surface Area Nanoporous Polymers for Reversible Hydrogen Storage. Chem. Mater. 2006, 18, 4430-4435. [CrossRef]

22. Germain, J.; Frechet, J.M.J.; Svec, F. Hypercrosslinked polyanilines with nanoporous structure and high surface area: Potential adsorbents for hydrogen storage. J. Mater. Chem. 2007, 17, 4989-4997. [CrossRef]

23. Germain, J.; Svec, F.; Frechet, J.M.J. Preparation of size-selective nanoporous polymer networks of aromatic rings: Potential adsorbents for hydrogen storage. Chem. Mater. 2008, 20, 7069-7076. [CrossRef]

24. Germain, J.; Frechet, J.M.J.; Svec, F. Nanoporous Polymers for Hydrogen Storage. Small 2009, 5, 1098-1111. [CrossRef] [PubMed]

25. Germain, J.; Frechet, J.M.J.; Svec, F. Nanoporous, hypercrosslinked polypyrroles: Effect of crosslinking moiety on pore size and selective gas adsorption. Chem. Commun. 2009, 12, 1526-1528. [CrossRef]

26. Broom, D.P.; Hirscher, M. Irreproducibility in hydrogen storage material research. Energy Environ. Sci. 2016, 9, 3368-3380. [CrossRef]

27. Fakirov, S. Editorial corner-A personal view hydrogen storage and polymers. Express Polym. Lett. 2017, 11, 162. [CrossRef]

28. Rosi, N.L.; Eckert, J.; Eddaoudi, M.; Vodak, D.T.; Kim, J.; O’Keeffe, M.; Yaghi, O.M. Hydrogen storage in microporous metalorganic frameworks. Science 2003, 300, 1127-1129. [CrossRef]

29. Rowsell, J.L.C.; Eckert, J.; Yaghi, O.M. Characterization of $\mathrm{H}_{2}$ binding sites in prototypical metal-organic frameworks by inelastic neutron scattering. J. Am. Chem. Soc. 2005, 127, 14904-14910. [CrossRef]

30. Li, Y.; Yang, R.T. Hydrogen storage in metal-organic frameworks by bridged hydrogen spillover. J. Am. Chem. Soc. 2006, 128, 8136-8137. [CrossRef] [PubMed]

31. Buda, C.; Dunietz, B.D. Hydrogen Physisorption on the Organic Linker in Metal Organic Frameworks: Ab Initio Computational Study. J. Phys. Chem. B 2006, 110, 10479-10484. [CrossRef]

32. Li, J.; Cheng, S.; Zhao, Q.; Long, P.; Dong, J. Synthesis and hydrogen storage behavior on metal-organic framework MOF-5. Int Ass. Hydrogen Energy 2009, 34, 1377-1382. [CrossRef]

33. Murray, L.J.; Dinca, M.; Long, J.R. Hydrogen storage in metal-organic frameworks. Chem. Soc. Rev. 2009, 38, 1294-1314. [CrossRef] [PubMed]

34. Han, S.S.; Mendoza-Cortes, J.L.; Goddard, W.A., III. Recent advances on simulation and theory of hydrogen storage in metalorganic frameworks and covalent organic frameworks. Chem. Soc. Rev. 2009, 38, 1460-1476. [CrossRef]

35. Hirscher, M. Hydrogen storage by cryoadsorption in ultrahigh porosity metal-organic frameworks. Angew. Chem. Int. Ed. 2011, 50, 581-958. [CrossRef]

36. Hirscher, M.; Panella, B.; Schmitz, B. Metal-organic frameworks for hydrogen storage. Micropor. Mesopor. Mater. 2010, 129, 335-339. [CrossRef]

37. Tranchemontagne, D.J.; Park, K.S.; Furukawa, H.; Eckert, J.; Knobler, C.B.; Yaghi, O.M. Hydrogen storage in new metal-organic frameworks. J. Phys. Chem. C 2012, 116, 13143-13151. [CrossRef]

38. Goldsmith, J.; Wong-Foy, A.G.; Cafarella, M.J.; Siegel, D.J. Theoretical limits of hydrogen storage in metal-organic frameworks: Opportunities and trade-offs. Chem. Mater. 2013, 25, 3373-3382. [CrossRef]

39. Chavan, S.M.; Zavorotynska, O.; Lamberti, C.; Bordiga, $\mathrm{S} . \mathrm{H}_{2}$ interaction with divalent cations in isostructural MOFs: A key study for variable temperature infrared spectroscopy. Dalton Trans. 2013, 42, 12586-12595. [CrossRef]

40. Suh, M.P.; Park, H.J.; Prasad, T.K.; Lim, D.-W. Hydrogen Storage in Metal-Organic Frameworks. Chem. Rev. 2012, 112, 782-835. [CrossRef] 
41. Kloutse, A.F.; Zacharia, R.; Cossement, D.; Chahine, R.; Balderas-Xicohtencatl, R.; Oh, H.; Streppel, B.; Schlichtenmayer, M.; Hirscher, M. Isosteric heat of hydrogen adsorption on MOFs: Comparison between adsorption calorimetry, sorption isosteric method, and analytical models. Appl. Phys. A 2015, 121, 1417-1424. [CrossRef]

42. Schoedel, A.; Ji, Z.; Yaghi, O.M. The role of metal-organic frameworks in a carbon-neutral energy cycle. Nat. Energy 2016, 1, 16034. [CrossRef]

43. Nandasiri, M.I.; Jambovane, S.R.; Mcgrail, B.P.; Schaef, H.T. Adsorption, separation and catalytic properties of densified metal-organic frameworks. Coord. Chem. Rev. 2016, 311, 38-52. [CrossRef]

44. Ullman, A.M.; Brown, J.W.; Foster, M.E.; Léonard, F.; Leong, K.; Stavila, V.; Allendorf, M.D. Transforming MOFs for energy applications using the guest@MOF concept. Inorg. Chem. 2016, 55, 7233-7249. [CrossRef]

45. Maity, D.K.; Halder, A.; Pahari, G.; Haque, F.; Ghoshal, D. Hydrogen uptake by an inclined polycatenated dynamic metal-organic framework based material. Inorg. Chem. 2017, 56, 713-716. [CrossRef] [PubMed]

46. Lyu, H.; Zhang, Q.; Wang, Y.; Duan, J. Unified meso-pores and dense $\mathrm{Cu}^{2+}$ sites in porous coordination polymers for highly efficient gas storage and separation. Dalton Trans. 2018, 47, 4424-4427. [CrossRef] [PubMed]

47. Zhao, F.-J.; Tan, Y.-X.; Wang, W.; Ju, Z.; Yuan, D. Optimizing $\mathrm{H}_{2}, \mathrm{D}_{2}$, and $\mathrm{C}_{2} \mathrm{H}_{2}$ sorption properties by tuning the pore apertures in metal-organic frameworks. Inorg. Chem. 2018, 57, 13312-13317. [CrossRef]

48. Ahmed, A.; Seth, S.; Purewal, J.; Wong-Foy, A.G.; Veenstra, M.; Matzger, A.J.; Siegel, D.J. Exceptional hydrogen storage achieved by screening nearly half a million metal-organic frameworks. Nat. Commun. 2019, 10, 1568. [CrossRef]

49. Molefe, L.Y.; Musyoka, N.M.; Ren, J.; Langmi, H.W.; Mathe, M. Polymer-based shaping strategy for zeolite templated carbons (ZTC) and their metal organic framework (MOF) composites for improved hydrogen storage properties. Front. Chem. 2019, 7, 864. [CrossRef]

50. Zhang, X.; Lin, R.-B.; Wang, J.; Wang, B.; Liang, B.; Yildirim, T.; Zhang, J.; Zhou, W.; Chen, B. Optimization of the pore structures of mofs for record high hydrogen volumetric working capacity. Adv. Mater. 2020, 32, 1907995. [CrossRef]

51. Yurdus, A.; Yürüm, A.; Yürüm, Y. Engineering MIL-88B crystallites for enhanced $\mathrm{H}_{2}$ uptake capacity: The role of ultramicropores. Int. J. Energy Res. 2020, 44, 2875-2888. [CrossRef]

52. Gupta, M.; Chatterjee, N.; De, D.; Saha, R.; Kumar Chattaraj, P.; Oliver, C.L.; Bharadwaj, P.K. Metal-organic frameworks of Cu(II) constructed from functionalized ligands for high capacity $\mathrm{H}_{2}$ and $\mathrm{CO}_{2}$ gas adsorption and catalytic studies. Inorg. Chem. 2020, 59, 1810-1822. [CrossRef]

53. Liu, Y.; Huang, D.; Cheng, M.; Liu, Z.; Lai, C.; Zhang, C.; Zhou, C.; Xiong, W.; Qin, L.; Shao, B.; et al. Metal sulfide/MOF-based composites as visible-light-driven photocatalysts for enhanced hydrogen production from water splitting. Coord. Chem. Rev. 2020, 409, 213220. [CrossRef]

54. Yu, S.; Jing, G.; Li, S.; Li, Z.; Ju, X. Tuning the hydrogen storage properties of MOF-650: A combined DFT and GCMC simulations study. Int. J. Hydrogen Energy 2020, 45, 6757-6764. [CrossRef]

55. Liu, J.; Mukherjee, S.; Wang, F.; Fischer, R.A.; Zhang, J. Homochiral metal-organic frameworks for enantioseparation. Chem. Soc. Rev. 2021, 50, 5706-5745. [CrossRef]

56. Tan, Y.X.; Wang, F.; Zhang, J. Design and synthesis of multifunctional metal-organic zeolites. Chem. Soc. Rev. 2018, 47, 2130-2144. [CrossRef]

57. Zhang, H.X.; Hong, Q.L.; Li, J.; Wang, F.; Huang, X.; Chen, S.; Tu, W.; Yu, D.; Xu, R.; Zhou, T.; et al. Isolated square-planar copper center in boron imidazolate nanocages for photocatalytic reduction of $\mathrm{CO}_{2}$ to CO. Angew. Chem. Int. Ed. 2019, 58, 11752-11756. [CrossRef]

58. Sun, Y.; Lu, D.F.; Sun, Y.; Gao, M.Y.; Zheng, N.; Gu, C.; Wang, F.; Zhang, J. Large titanium-oxo clusters as precursors to synthesize the single crystals of Ti-MOFs. ACS Mater. Lett. 2021, 3, 64-68. [CrossRef]

59. Thommes, M.; Kaneko, K.; Neimark, A.V.; Olivier, J.P.; Rodriguez-Reinoso, F.; Rouquerol, J.; Sing, K.S.W. Physisorption of gases, with special reference to the evaluation of surface area and pore size distribution (IUPAC Technical Report). Pure Appl. Chem. 2015, 87, 1051-1069. [CrossRef]

60. Rosi, N.L.; Eddaoudi, M.; Kim, J.; O'Keeffe, M.; Yaghi, O.M. Infinite secondary building units and forbidden catenation in metal-organic frameworks. Angew. Chem. Int. Ed. 2002, 41, 284-287. [CrossRef]

61. Llewellyn, P.L.; Rodriquez-Reinoso, F.; Rouqerol, J.; Seaton, N. Characterization of Porous Solids VII; Elsevier: Oxford, UK, 2007; pp. 750.

62. Senkovska, I.; Kaskel, S. Ultrahigh porosity in mesoporous MOFs: Promises and limitations. Chem. Commun. 2014, 50, 7089-7098. [CrossRef] [PubMed]

63. Rouquerol, J.; Rouquerol, F.; Sing, K.S.W.; Llewellyn, P.; Maurin, G. Adsorption by Powders and Porous Solids: Principles, Methodology and Applications, 2nd ed.; Elsevier: Oxford, UK, 2014; 630p.

64. Parilla, P.A.; Gross, K.; Hurst, K.; Gennett, T. Recommended volumetric capacity definitions and protocols for accurate, standardized and unambiguous metrics for hydrogen storage materials. Appl. Phys. A 2016, 122, 201. [CrossRef]

65. Dang, S.; Zhu, Q.-L.; Xu, Q. Nanomaterials Derived from Metal-Organic Frameworks. Nat. Rev. Mater. 2018, 3, 17045. [CrossRef]

66. Giraldo, L.; Rodriguez-Estupiñán, P. Moreno-Piraján, J.C. Isosteric Heat: Comparative study between Clausius-Clapeyron, CSK and adsorption calorimetry methods. Processes 2019, 7, 203. [CrossRef]

67. Chakraborty, A.; Saha, B.B.; Koyama, S.; Ng, K.C. Specific heat capacity of a single component adsorbent-adsorbate system. App. Phys. Lett. 2006, 89, 171902. [CrossRef] 
68. Li, H.; Eddaoudi, M.; Groy, T.L.; Yaghi, O.M. Establishing microporosity in open metal-organic frameworks: gas sorption isotherms for $\mathrm{Zn}(\mathrm{BDC})$ (BDC = 1,4-Benzenedicarboxylate). J. Am. Chem. Soc. 1998, 120, 8571-8572. [CrossRef]

69. Li, H.; Eddaoudi, M.; O'Keeffe, M.; Yaghi, O.M. Design and synthesis of an exceptionally stable and highly porous metal-organic framework. Nature 1999, 402, 276-279. [CrossRef]

70. Ding, M.; Flaig, R.W.; Jiang, H.L.; Yaghi, O.M. Carbon capture and conversion using metal-organic frameworks and MOF-based materials. Chem. Soc. Rev. 2019, 48, 2783-2828. [CrossRef]

71. Gangu, K.K.; Maddila, S.; Mukkamala, S.B.; Jonnalagadda, S.B. Characteristics of MOF, MWCNT and graphene containing materials for hydrogen storage: A review. J. Energy Chem. 2019, 30, 132-144. [CrossRef]

72. Rojas, S.; Arenas-Vivo, A.; Horcajada, P. Metal-organic frameworks: A novel platform for combined advanced therapies. Cord. Chem. Rev. 2019, 388, 202-226. [CrossRef]

73. Eddaoudi, M.; Kim, J.; Rosi, N.; Vodak, D.; Wachter, J.; O’Keeffe, M.; Yaghi, O.M. Systematic design of pore size and functionality in isoreticular MOFs and their application in methane storage. Science 2002, 295, 469-472. [CrossRef] [PubMed]

74. Ahmed, A.; Liu, Y.; Purewal, J.; Tran, L.D.; Wong-Foy, A.G.; Veenstra, M.; Matzger, A.J.; Siegel, D.J. Balancing gravimetric and volumetric hydrogen density in MOFs. Energy Environ. Sci. 2017, 10, 2459-2471. [CrossRef]

75. Cavka, J.H.; Jakobsen, S.; Olsbye, U.; Guillou, N.; Lamberti, C.; Bordiga, S.; Lillerud, K.P. A new zirconium inorganic building brick forming metal organic frameworks with exceptional stability. J. Am. Chem. Soc. 2008, 130, 13850-13851. [CrossRef]

76. Biswas, S.; Zhang, J.; Li, Z.; Liu, Y.Y.; Grzywa, M.; Sun, L.; Volkmer, D.; Van Der Voort, P. Enhanced selectivity of $\mathrm{CO}_{2}$ over $\mathrm{CH}_{4}$ in sulphonate-, carboxylate- and iodo-functionalized UiO-66 frameworks. Dalton Trans. 2013, 42, 4730-4737. [CrossRef] [PubMed]

77. Lu, W.; Wei, Z.; Gu, Z.Y.; Liu, T.F.; Park, J.; Park, J.; Tian, J.; Zhang, M.; Zhang, Q.; Gentle, T.; et al. Tuning the structure and function of metal-organic frameworks via linker design. Chem. Soc. Rev. 2014, 43, 5561-5593. [CrossRef] [PubMed]

78. Chui, S.S.; Los, S.M.F.; Charmant, J.P.H.; Open, A.G.; Williams, I.D. A chemically functionalizable nanoporous material $\left[\mathrm{Cu}_{3}(\mathrm{TMA})_{2}\left(\mathrm{H}_{2} \mathrm{O}\right)_{3}\right]_{n}$. Science 1999, 38, 1148-1150. [CrossRef]

79. Mason, J.A.; Veenstra, M.; Long, J.R. Evaluating metal-organic frameworks for natural gas storage. Chem. Sci. $2014,5,32-51$. [CrossRef]

80. Chen, Z.; Li, P.; Anderson, R.; Wang, X.; Zhang, X.; Robison, L.; Redfern, L.R.; Moribe, S.; Islamoglu, T.; Gómez-Gualdrón, D.A.; et al. Balancing volumetric and gravimetric uptake in highly porous materials for clean energy. Science 2020, 368, 297-303. [CrossRef]

81. Frost, H.; Duren, T.; Snurr, R.Q. Effects of surface area, free volume, and heat of adsorption on hydrogen uptake in metal-organic frameworks. J. Phys. Chem. B 2006, 110, 9565-9570. [CrossRef]

82. Furukawa, H.; Ko, N.; Go, Y.B.; Aratani, N.; Choi, S.B.; Choi, E.; Yazaydin, A.O.; Snurr, R.Q.; O'Keeffe, M.; Kim, J.; et al. Ultrahigh porosity in metal-organic frameworks. Science 2010, 329, 424-428. [CrossRef]

83. Panella, B.; Hirscher, M.; Pütter, H.; Müller, U. Hydrogen adsorption in metal-organic frameworks: Cu-MOFs and Zn-MOFs compared. Adv. Funct. Mater. 2006, 16, 520-524. [CrossRef]

84. Yang, S.J.; Jung, H.; Kim, T.; Im, J.H.; Park, C.R. Effects of structural modifications on the hydrogen storage capacity of MOF-5. Int. J. Hydrogen Energy 2012, 37, 5777-5783. [CrossRef]

85. Hönicke, I.M.; Senkovska, I.; Bon, V.; Baburin, I.A.; Bönisch, N.; Raschke, S.; Evans, J.D.; Kaskel, S. Balancing mechanical stability and ultrahigh porosity in crystalline framework materials. Angew. Chem. Int. Ed. 2018, 57, 13780-13783. [CrossRef] [PubMed]

86. Furukawa, H.; Miller, M.A.; Yaghi, O.M. Independent verification of the saturation hydrogen uptake in MOF-177 and establishment of a benchmark for hydrogen adsorption in metal-organic frameworks. J. Mater. Chem. 2007, 17, 3197-3204. [CrossRef]

87. Chavan, S.; Vitillo, J.G.; Gianolio, D.; Zavorotynska, O.; Civalleri, B.; Jakobsen, S.; Nilsen, M.H.; Valenzano, L.; Lamberti, C.; Lillerud, K.P.; et al. $\mathrm{H}_{2}$ storage in isostructural UiO-67 and UiO-66 MOFs. Phys. Chem. Chem. Phys. 2012, 14, 1614-1626. [CrossRef]

88. Liu, J.; Wang, W.; Luo, Z.; Li, B.; Yuan, D. Microporous metal-organic framework based on ligand-truncation strategy with high performance for gas adsorption and separation. Inorg. Chem. 2017, 56, 10215-10219. [CrossRef]

89. Rowsell, J.L.C.; Millward, A.R.; Park, K.S.; Yaghi, O.M. Hydrogen sorption in functionalized metal-organic frameworks. J. Am. Chem. Soc. 2004, 126, 5666-5667. [CrossRef]

90. Wong-Foy, A.G.; Matzger, A.J.; Yaghi, O.M. Exceptional $\mathrm{H}_{2}$ saturation uptake in microporous metal-organic frameworks. J. Am. Chem. Soc. 2006, 128, 3494-3495. [CrossRef]

91. Kaskel, S. Metal-Organic Frameworks: Design and Application; MacGillivray, L.R., Ed.; Wiley: Hoboken, NJ, USA, 2010; 349p.

92. Batten, S.R. Topology of interpenetration. CrystEngComm 2001, 3, 67-72. [CrossRef]

93. Zhou, H.-C.; Ma, S.Q.; Sun, D.F.; Ambrogio, M.; Fillinger, J.A.; Parkin, S. Framework-catenation isomerism in metal-organic frameworks and its impact on hydrogen uptake. J. Am. Chem. Soc. 2007, 129, 1858-1859.

94. Farha, O.K.; Malliakas, C.D.; Kanatzidis, M.G.; Hupp, J.T. Control over catenation in metal-organic frameworks via rational design of the organic building block. J. Am. Chem. Soc. 2010, 132, 950-952. [CrossRef]

95. Zhang, J.; Wojtas, L.; Larsen, R.W.; Eddaoudi, M.; Zaworotko, M.J. Temperature and concentration control over interpenetration in a metal-organic material. J. Am. Chem. Soc. 2009, 131, 17040-17041. [CrossRef]

96. Shekhah, O.; Wang, H.; Paradinas, M.; Ocal, C.; Schupbach, B.; Terfort, A.; Zacher, D.; Fischer, R.A.; Wöll, C. Controlling interpenetration in metal-organic frameworks by liquid-phase epitaxy. Nat. Mater. 2009, 8, 481-484. [CrossRef]

97. Rowsell, J.L.; Yaghi, O.M. Strategies for hydrogen storage in metal-organic frameworks. Angew. Chem. Int. Ed. 2005, 44, 4670-4679. [CrossRef] 
98. Kanoo, P.; Matsuda, R.; Higuchi, M.; Kitagawa, S.; Maji, T.K. New interpenetrated copper coordination polymer frameworks having porous properties. Chem. Mater. 2009, 21, 5860-5866. [CrossRef]

99. Ryan, P.; Broadbelt, L.J.; Snurr, R.Q. Is catenation beneficial for hydrogenstorage in metal-organic frameworks? Chem. Commun. 2008, 44, 4132-4134. [CrossRef] [PubMed]

100. Park, H.J.; Suh, M.P. Mixed-ligand metal-organic frameworks with large pores: Gas sorption properties and single-crystal-tosingle-crystal transformation on guest exchange. Chem. Eur. J. 2008, 14, 8812-8821. [CrossRef] [PubMed]

101. Koh, K.; Wong-Foy, A.G.; Matzger, A.J. Coordination copolymerization mediated by $\mathrm{Zn}_{4} \mathrm{O}\left(\mathrm{CO}_{2} \mathrm{R}\right)_{6}$ metal clusters: A balancing act between statistics and geometry. J. Am. Chem. Soc. 2010, 132, 15005-15010. [CrossRef]

102. Furukawa, H.; Cordova, K.E.; O’Keefe, M.; Yaghi, O.M. The Chemistry and applications of metal-organic frameworks. Science 2013, 341, 1230444. [CrossRef]

103. Liu, G.; Chernikova, V.; Liu, Y.; Zhang, K.; Belmabkhout, Y.; Shekhah, O.; Zhang, C.; Yi, S.; Eddaoudi, M.; Koros, W.J. Mixed matrix formulations with MOF molecular sieving for key energy-intensive separations. Nat. Mater. 2018, 17, 283-289. [CrossRef]

104. Schneemann, A.; Bon, V.; Schwedler, I.; Senkovska, I.; Kaskel, S.; Fischer, R.A. Flexible metal-organic frameworks. Chem. Soc. Rev. 2014, 43, 6062-6096. [CrossRef] [PubMed]

105. Yan, Y.; Yang, S.; Blake, A.J.; Lewis, W.; Poirier, E.; Barnett, S.A.; Champness, N.R.; Schröder, M. A mesoporous metal-organic framework constructed from a nanosized $C_{3}$-symmetric linker and $\left[\mathrm{Cu}_{24}\right.$ (isophthalate) $\left.{ }_{24}\right]$ cuboctahedra. Chem. Commun. 2011, 47, 9995-9997. [CrossRef] [PubMed]

106. Wei, Y.-S.; Chen, K.-J.; Liao, P.-Q.; Zhu, B.-Y.; Lin, R.-B.; Zhou, H.-L.; Wang, B.-Y.; Xue, W.; Zhang, J.-P.; Chen, X.-M. Turning on the flexibility of isoreticular porous coordination frameworks for drastically tunable framework breathing and thermal expansion. Chem. Sci. 2013, 4, 1539-1546. [CrossRef]

107. Yang, S.; Liu, L.; Sun, J.; Thomas, K.M.; Davies, A.J.; George, M.W.; Blake, A.J.; Hill, A.H.; Fitch, A.N.; Tang, C.C.; et al. Irreversible network transformation in a dynamic porous host catalyzed by sulfur dioxide. J. Am. Chem. Soc. 2013, 135, 4954-4957. [CrossRef]

108. Ferey, G.; Serre, C. Large breathing effects in three-dimensional porous hybrid matter: Facts, analyses, rules and consequences. Chem. Soc. Rev. 2009, 38, 1380-1399. [CrossRef]

109. Ferey, G. Nanoporous materials: A selective magnetic sponge. Nat. Mater. 2003, 2, 136-137. [CrossRef]

110. Maspoch, D.; Ruiz-Molina, D.; Wurst, K.; Domingo, N.; Cavallini, M.; Biscarini, F.; Tejada, J.; Rovira, C.; Veciana, J. A nanoporous molecular magnet with reversible solvent-induced mechanical and magnetic properties. Nat. Mater. 2003, 2, 190-195. [CrossRef]

111. Lin, Z.-J.; Lü, J.; Hong, M.; Cao, R. Metal-organic frameworks based on flexible ligands (FL-MOFs): Structures and applications. Chem. Soc. Rev. 2014, 43, 5867-5895. [CrossRef]

112. Chang, Z.; Zhang, D.-S.; Chen, Q.; Li, R.-F.; Hu, T.-L.; Bu, X.-H. Rational construction of 3D pillared metal-organic frameworks: Synthesis, structures, and hydrogen adsorption properties. Inorg. Chem. 2011, 50, 7555-7562. [CrossRef]

113. Montes-Andrés, H.; Leo, P.; Orcajo, G.; Rodríguez-Diéguez, A.; Choquesillo-Lazarte, D.; Martos, C.; Botas, J.Á.; Calleja, G. Synthesis, structural features, and hydrogen adsorption properties of three new flexible sulfur-containing metal-organic frameworks. Cryst. Growth Des. 2020, 20, 6707-6714. [CrossRef]

114. Li, X.-L.; Liu, G.-Z.; Xin, L.-Y.; Wang, L.-Y. A novel metal-organic framework displaying reversibly shrinking and expanding pore modulation. CrystEngComm 2012, 14, 5757-5760. [CrossRef]

115. Kitagawa, S.; Uemura, K. Dynamic porous properties of coordination polymers inspired by hydrogen bonds. Chem. Soc. Rev. 2005, 34, 109-119. [CrossRef] [PubMed]

116. Barthelet, K.; Marrot, J.; Riou, D.; Ferey, G. A breathing hybrid organic-inorganic solid with very large pores and high magnetic characteristics. Angew. Chem. Int. Ed. 2002, 41, 281-284. [CrossRef]

117. Serre, C.; Millange, F.; Thouvenot, C.; Noguès, M.; Marsolier, G.; Louër, D.; Ferey, G. Very large breathing effect in the first nanoporous chromium (III)-based solids: MIL-53 or CrIII $(\mathrm{OH}) \cdot\left\{\mathrm{O}_{2} \mathrm{C}-\mathrm{C}_{6} \mathrm{H}_{4}-\mathrm{CO} 2\right\} \cdot\left\{\mathrm{HO}_{2} \mathrm{C}-\mathrm{C}_{6} \mathrm{H}_{4}-\mathrm{CO}_{2} \mathrm{H}\right\}_{\mathrm{x}} \cdot \mathrm{H}_{2} \mathrm{O}_{\mathrm{y}}$. J. Am. Chem. Soc. 2002, 124, 13519-13526. [CrossRef] [PubMed]

118. Surble, S.; Serre, C.; Mellot-Draznieks, C.; Millangeand, F.; Ferey, G. A new isoreticular class of metal-organic-frameworks with the MIL-88 topology. Chem. Commun. 2006, 3, 284-286. [CrossRef]

119. Serre, C.; Mellot-Draznieks, C.; Surble, S.; Audebrand, N.; Filinchuk, Y.; Ferey, G. Role of solvent-host interactions that lead to very large swelling of hybrid frameworks. Science 2007, 315, 1828-1831. [CrossRef]

120. Broom, D.P.; Webb, C.J.; Fanourgakis, G.S.; Froudakis, G.E.; Trikalitis, P.N.; Hirscher, M. Concepts for improving hydrogen storage in nanoporous materials. Int. J. Hydrogen Energy 2019, 44, 7768-7779. [CrossRef]

121. Lochan, R.C.; Head-Gordon, M. Computational studies of molecular hydrogen binding affinities: The role of dispersion forces, electrostatics, and orbital interactions. Phys. Chem. Chem. Phys. 2006, 8, 1357-1370. [CrossRef]

122. Bhatia, S.K.; Myers, A.L. Optimum Conditions for Adsorptive Storage. Langmuir 2006, 22, 1688-1700. [CrossRef]

123. Frost, H.; Snurr, R.Q. Design Requirements for Metal-Organic Frameworks as Hydrogen Storage Materials. J. Phys. Chem. C 2007, 111, 18794-18803. [CrossRef]

124. Bae, Y.-S.; Snurr, R.Q. Optimal isosteric heat of adsorption for hydrogen storage and delivery using metal-organic frameworks. Microp. Mesopor. Mater. 2010, 132, 300-303. [CrossRef]

125. Li, B.; Chrzanowski, M.; Zhang, Y.; Ma, S. Application of metal-organic frameworks featuring multi-functional sites. Coord. Chem. Rev. 2016, 307, 106-129. [CrossRef] 
126. Dinca, M.; Long, J.R. High-enthalpy hydrogen adsorption in cation-exchanged variants of the microporous metal-organic framework $\mathrm{Mn}_{3}\left[\left(\mathrm{Mn}_{4} \mathrm{Cl}\right)_{3}(\mathrm{BTT})_{8}\left(\mathrm{CH}_{3} \mathrm{OH}\right)_{10}\right]_{2}$. J. Am. Chem. Soc. 2007, 129, 11172-11176. [CrossRef]

127. Nouar, F.; Eckert, J.; Eubank, J.F.; Forster, P.; Eddaoudi, M.J. Zeolite-like metal-organic frameworks (zmofs) as hydrogen storage platform: Lithium and magnesium ion-exchange and H2-(rho-ZMOF) interaction studies. Am. Chem. Soc. 2009, 131, 2864-2870. [CrossRef]

128. Cheon, Y.E.; Suh, M.P. Selective gas adsorption in a microporous metal-organic framework constructed of $\mathrm{Co}^{\mathrm{II}} 4 \mathrm{clusters}$. Chem. Commun. 2009, 45, 2296-2298. [CrossRef] [PubMed]

129. Ma, S.; Zhou, H.-C. A metal-organic framework with entatic metal centers exhibiting high gas adsorption affinity. J. Am. Chem. Soc. 2006, 128, 11734-11735. [CrossRef]

130. Kapelewski, M.T.; Runčevski, T.; Tarver, J.D.; Jiang, H.Z.H.; Hurst, K.E.; Parilla, P.A.; Ayala, A.; Gennett, T.; FitzGerald, S.A.; Brown, C.M.; et al. Record high hydrogen storage capacity in the metal-organic framework ni2 $(m$-dobdc) at near-ambient temperatures. Chem. Mater. 2018, 30, 8179-8189. [CrossRef] [PubMed]

131. Kosal, M.E.; Chou, J.-H.; Wilson, S.R.; Suslick, K.S. A functional zeolite analogue assembled from metalloporphyrins. Nat. Mater. 2002, 1, 118-121. [CrossRef] [PubMed]

132. Zimmer, B.; Hutin, M.; Bulach, V.; Hosseini, M.W.; Cian, A.D.; Kyritsakas, N. Coordination polymers based on porphyrin and copper: The influence of the crystallization solvents on the dimensionality of the network. New J. Chem. 2002, 26, 1532-1535. [CrossRef]

133. Deiters, E.; Bulach, V.; Hosseini, M.W. Reversible single-crystal-to-single-crystal guest exchange in a 3-D coordination network based on a zinc porphyrin. Chem. Commun. 2005, 31, 3906-3908. [CrossRef] [PubMed]

134. Kuhn, E.; Bulach, V.; Hosseini, M.W. Molecular tectonics: Control of pore size and polarity in 3-D hexagonal coordination networks based on porphyrins and a zinc cation. Chem. Commun. 2008, 41, 5104-5106. [CrossRef] [PubMed]

135. Ohmura, T.; Usuki, A.; Fukumori, K.; Ohta, T.; Ito, M.; Tatsumi, K. New porphyrin-based metal-organic framework with high porosity: 2-d infinite 22.2-Å square-grid coordination network. Inorg. Chem. 2006, 45, 7988-7990. [CrossRef]

136. Alkordi, M.H.; Liu, Y.L.; Larsen, R.W.; Eubank, J.F.; Eddaoudi, M. Zeolite-like metal-organic frameworks as platforms for applications: On metalloporphyrin-based catalysts. J. Am. Chem. Soc. 2008, 130, 12639-12641. [CrossRef] [PubMed]

137. Chen, L.; Yang, Y.; Jiang, D.L. CMPs as scaffolds for constructing porous catalytic frameworks: A built-in heterogeneous catalyst with high activity and selectivity based on nanoporous metalloporphyrin polymers. J. Am. Chem. Soc. 2010, 132, 9138-9143. [CrossRef] [PubMed]

138. Farha, O.K.; Shultz, A.M.; Sarjeant, A.A.; Nguyen, S.T.; Hupp, J.T. Active-site-accessible, porphyrinic metal-organic framework materials. J. Am. Chem. Soc. 2011, 133, 5652-5655. [CrossRef]

139. Song, F.; Wang, C.; Falkowski, J.M.; Ma, L.; Lin, W.J. Isoreticular chiral metal-organic frameworks for asymmetric alkene epoxidation: Tuning catalytic activity by controlling framework catenation and varying open channel sizes. Am. Chem. Soc. 2010, 132, 15390-15398. [CrossRef]

140. Kitaura, R.; Onoyama, G.; Sakamoto, H.; Matsuda, R.; Noro, S.; Kitagawa, S. Immobilization of a metallo schiff base into a microporous coordination polymer. Angew. Chem. Int. Ed. 2004, 43, 2684-2687. [CrossRef]

141. Wu, H.-B.; Wang, Q.-M. Construction of heterometallic cages with tripodal metalloligands. Angew. Chem. Int. Ed. 2009, 48, 7343-7345. [CrossRef] [PubMed]

142. Sakamoto, H.; Matsuda, R.; Bureekaew, S.; Tanaka, D.; Kitagawa, S. A porous coordination polymer with accessible metal sites and its complementary coordination action. Chem. Eur. J. 2009, 15, 4985-4989. [CrossRef]

143. Roesky, P.W.; Bhunia, A.; Lan, Y.; Powell, A.K.; Kureti, S. Salen-based metal-organic frameworks of nickel and the lanthanides. Chem. Commun. 2011, 47, 2035-2037. [CrossRef] [PubMed]

144. Shultz, A.M.; Farha, O.K.; Adhikari, D.; Sarjeant, A.A.; Hupp, J.T.; Nguyen, S.T. Selective surface and near-surface modification of a noncatenated, catalytically active metal-organic framework material based on Mn(salen) struts. Inorg. Chem. 2011, 50, 3174-3176. [CrossRef] [PubMed]

145. Shultz, A.M.; Sarjeant, A.A.; Farha, O.K.; Hupp, J.T.; Nguyen, S.T. Post-synthesis modification of a metalorganic framework to form metallosalen-containing mof materials. J. Am. Chem. Soc. 2011, 133, 13252-13255. [CrossRef]

146. Wu, C.-D.; Hu, A.; Zhang, L.; Lin, W.J. A homochiral porous metal-organic framework for highly enantioselective heterogeneous asymmetric catalysis. J. Am. Chem. Soc. 2005, 127, 8940-8941. [CrossRef] [PubMed]

147. Oisaki, K.; Li, Q.; Furukawa, H.; Czaja, A.U.; Yaghi, O.M. A metal-organic framework with covalently bound organometallic complexes. J. Am. Chem. Soc. 2010, 132, 9262-9264. [CrossRef] [PubMed]

148. Bloch, E.D.; Britt, D.; Lee, C.; Doonan, C.; Uribe-Romo, F.J.; Furukawa, H.; Long, J.R.; Yaghi, O.M. Metal insertion in a microporous metal-organic framework lined with 2,2'-bipyridine. J. Am. Chem. Soc. 2010, 132, 14382-14384. [CrossRef]

149. Gadzikwa, T.; Farha, O.K.; Mulfort, K.L.; Hupp, J.T.; Nguyen, S.T. A Zn-based, pillared paddlewheel MOF containing free carboxylic acids via covalent post-synthesis elaboration. Chem. Commun. 2009, 45, 3720-3722. [CrossRef]

150. Doonan, C.J.; Morris, W.; Furukawa, H.; Yaghi, O.M. Isoreticular metalation of metal-organic frameworks. J. Am. Chem. Soc. 2009, 131, 9492-9493. [CrossRef]

151. Kaye, S.S.; Long, J.R. Matrix isolation chemistry in a porous metal-organic framework: photochemical substitutions of $\mathrm{N}_{2}$ and $\mathrm{H}_{2}$ in $\mathrm{Zn}_{4} \mathrm{O}$ [(n6-1,4-benzenedicarboxylate $\left.) \mathrm{Cr}(\mathrm{CO})_{3}\right]_{3}$. J. Am. Chem. Soc. 2008, 130, 806-807. [CrossRef] 
152. Dinca, M.; Long, J.R. Structure and charge control in metal-organic frameworks based on the tetrahedral ligand tetrakis(4tetrazolylphenyl)methane. Chem. Eur. J. 2008, 14, 10280-10285. [CrossRef]

153. Allendorf, M.D.; Hulvey, Z.; Gennett, T.; Ahmed, A.; Autrey, T.; Camp, J.; Cho, E.S.; Furukawa, H.; Haranczyk, M.; Head-Gordon, M.; et al. An assessment of strategies for the development of solid-state adsorbents for vehicular hydrogen storage. Energy Environ. Sci. 2018, 11, 2784-2812. [CrossRef]

154. Botas, J.A.; Calleja, G.; Sanchez, M.; Orcajo, M.G. Cobalt doping of the MOF-5 framework and its effect on gas-adsorption properties. Langmuir 2010, 26, 5300-5303. [CrossRef] [PubMed]

155. Chen, Q.; Ma, Y.; Song, W.-C.; Chang, Z.; Li, J.-R.; Zhang, J.; Sun, H.-W.; Balbuena, P.B.; Bu, X.-H. Why porous materials have selective adsorptions: A rational aspect from electrodynamics. Inorg. Chem. 2017, 56, 2614-2620. [CrossRef]

156. Zhu, Q.-L.; Xu, Q. Metal-organic framework composites. Chem. Soc. Rev. 2014, 43, 5468-5512. [CrossRef] [PubMed]

157. Evans, J.D.; Sumby, C.J.; Doonan, C.J. Post-synthetic metalation of metal-organic frameworks. Chem. Soc. Rev. 2014, 43, 5933-5951. [CrossRef]

158. Kobayashi, H.; Mitsuka, Y.; Kitagawa, H. Metal nanoparticles covered with a metal-organic framework: From one-pot synthetic methods to synergistic energy storage and conversion functions. Inorg. Chem. 2016, 55, 7301-7310. [CrossRef]

159. Railey, P.; Song, Y.; Liu, T.; Li, Y. Metal organic frameworks with immobilized nanoparticles: Synthesis and applications in photocatalytic hydrogen generation and energy storage. Mater. Res. Bull. 2017, 96, 385-394. [CrossRef]

160. Ishida, T.; Nagaoka, M.; Akita, T.; Haruta, M. Deposition of gold clusters on porous coordination polymers by solid grinding and their catalytic activity in aerobic oxidation of alcohols. Chem. Eur. J. 2008, 14, 8456-8460. [CrossRef]

161. Pan, H.; Li, X.; Zhang, D.; Guan, Y.; Wu, P. Pt nanoparticles entrapped in mesoporous metal-organic frameworks MIL-101 as an efficient and recyclable catalyst for the asymmetric hydrogenation of $\alpha$-ketoesters. J. Mol. Catal. A Chem. 2013, 377, 108-114. [CrossRef]

162. Khajavi, H.; Stil, H.A.; Kuipers, H.; Gascon, J.; Kapteijn, F. Shape and transition state selective hydrogenations using egg-shell Pt-MIL-101(Cr) catalyst. ACS Catal. 2013, 3, 2617-2626. [CrossRef]

163. Du, W.; Chen, G.; Nie, R.; Li, Y.; Hou, Z. Highly dispersed Pt in MIL-101: An efficient catalyst for the hydrogenation of nitroarenes. Catal. Commun. 2013, 41, 56-59. [CrossRef]

164. Yadav, M.; Xu, Q. Catalytic chromium reduction using formic acid and metal nanoparticles immobilized in a metal-organic framework. Chem. Commun. 2013, 49, 3327-3329. [CrossRef] [PubMed]

165. Singh, A.K.; Xu, Q. Metal-organic framework supported bimetallic Ni-Pt nanoparticles as high-performance catalysts for hydrogen generation from hydrazine in aqueous solution. ChemCatChem 2013, 5, 3000-3004. [CrossRef]

166. Hermes, S.; Schröter, M.-K.; Schmid, R.; Khodeir, L.; Muhler, M.; Tissler, A.; Fischer, R.W.; Fischer, R.A. Metal@MOF: Loading of highly porous coordination polymers host lattices by metal organic chemical vapor deposition. Angew. Chem. Int. Ed. 2005, 44, 6237-6241. [CrossRef] [PubMed]

167. Hu, P.; Zhuang, J.; Chou, L.Y.; Lee, H.K.; Ling, X.Y.; Chuang, Y.C.; Tsung, C.K. Surfactant-directed atomic to mesoscale alignment: Metal nanocrystals encased individually in single-crystalline porous nanostructures. J. Am. Chem. Soc. 2014, 136, 10561-10564. [CrossRef] [PubMed]

168. Ohhashi, T.; Tsuruoka, T.; Matsuyama, T.; Takashima, Y.; Nawafune, H.; Minami, H.; Akamatsu, K.J. Metal nanocrystal/metalorganic framework core/shell nanostructure from selective self-assembly induced by localization of metal ion precursors on nanocrystal surface. Colloid Interface Sci. 2015, 451, 212-215. [CrossRef]

169. Li, G.; Kobayashi, H.; Taylor, J.M.; Ikeda, R.; Kubota, Y.; Kato, K.; Takata, M.; Yamamoto, T.; Toh, S.; Matsumura, S.; et al. Hydrogen storage in Pd nanocrystals covered with a metal-organic framework. Nat. Mater. 2014, 13, 802-806. [CrossRef]

170. Wang, Q.; Astruc, D. State of the art and prospects in metal-organic framework (MOF)based and MOF-derived nanocatalysis. Chem. Rev. 2020, 120, 1438-1511. [CrossRef]

171. Zlotea, C.; Campesi, R.; Cuevas, F.; Leroy, E.; Dibandjo, P.; Volkringer, C.; Loiseau, T.; Ferey, G.; Latroche, M. Pd nanoparticles embedded into a metal-organic framework: Synthesis, structural characteristics, and hydrogen sorption properties. J. Am. Chem. Soc. 2010, 132, 2991-2997. [CrossRef]

172. Malouche, A.; Blanita, G.; Lupu, D.; Bourgon, J.; Nelayah, J.; Zlotea, C. Hydrogen absorption in $1 \mathrm{~nm}$ Pd clusters confined in MIL-101(Cr). J. Mater. Chem. A 2017, 5, 23043-23052. [CrossRef]

173. Lestari, W.W.; Afifah, E.N.; Mohammed, O.; Saraswati, T.E.; Al-Adawiyah, R.; Kadja, G.T.M.; Widiastuti, N. DUT-5 modified Pd metal-nanoparticles: Synthesis, chemical stability, and hydrogen sorption studies. Mater. Res. Express 2019, 6, 1250d4. [CrossRef]

174. King, J.; Zhang, L.; Doszczeczko, S.; Sambalova, O.; Luo, H.; Rohman, F.; Phillips, O.; Borgschulte, A.; Hirscher, M.; Addicoat, M.; et al. How to functionalise metal-organic frameworks to enable guest nanocluster embedment. J. Mater. Chem. A 2020, 8, 4889-4897. [CrossRef]

175. Luzan, S.M.; Talyzin, A.V. Hydrogen adsorption in Pt catalyst/MOF-5 materials. Microporous Mesoporous Mater. 2010, 135, $201-205$. [CrossRef]

176. Campesi, R.; Cuevas, F.; Latroche, M.; Hirscher, M. Hydrogen spillover measurements of unbridged and bridged metal-organic frameworks-revisited. Phys. Chem. Chem. Phys. 2010, 12, 10457-10459. [CrossRef]

177. Wang, L.; Stuckert, N.R.; Chen, H.; Yang, R.T. Effects of Pt particle size on hydrogen storage on Pt-doped metal-organic framework IRMOF-8. J. Phys. Chem. C 2011, 115, 4793-4799. [CrossRef] 
178. Proch, S.; Herrmannsdofer, J.; Kempe, R.; Kern, C.; Jess, A.; Seyfarth, L.; Senker, J. Pt@MOF-177: Synthesis, room-temperature hydrogen storage and oxidation catalysis. Chem. Eur. J. 2008, 14, 8204-8212. [CrossRef]

179. Dixit, M.; Adit Maark, T.; Ghatak, K.; Ahuja, R.; Pal, S. Scandium-decorated MOF-5 as potential candidates for room temperature hydrogen storage: A solution for the clustering problem in MOFs. J. Phys. Chem. C 2012, 116, 17336-17342. [CrossRef]

180. Mukoyoshi, M.; Kobayashi, H.; Kusada, K.; Hayashi, M.; Yamada, T.; Maesato, M.; Taylor, J.M.; Kubota, Y.; Kato, K.; Takata, M.; et al. Hybrid materials of Ni NP@MOF prepared by a simple synthetic method. Chem. Commun. 2015, 51, 12463-12466. [CrossRef] [PubMed]

181. Liu, X.L.; Wang, R.; Zhang, M.Y.; Yuan, Y.P.; Xue, C. Dye-sensitized MIL-101 metal organic frameworks loaded with Ni/NiOx nanoparticles for efficient visible-light-driven hydrogen generation. Appl. Mater. 2015, 3, 104403. [CrossRef]

182. Zhen, W.L.; Gao, H.B.; Tian, B.; Ma, J.T.; Lu, G.X. Fabrication of low adsorption energy Ni-Mo cluster cocatalyst in metal-organic frameworks for visible photocatalytic hydrogen evolution. ACS Appl. Mater. Interfaces 2016, 8, 10808-10819. [CrossRef] [PubMed]

183. Zhen, W.L.; Ma, J.T.; Lu, G.X. Small-sized Ni(111) particles in metal-organic frameworks with low over-potential for visible photocatalytic hydrogen generation. Appl. Catal. B Environ. 2016, 190, 12-25. [CrossRef]

184. Shi, Y.; Yang, A.-F.; Cao, C.-S.; Zhao, B. Applications of MOFs: Recent advances in photocatalytic hydrogen production from water. Coord. Chem. Rev. 2019, 390, 50-75. [CrossRef]

185. Zhao, D.; Yan, D.; Zhou, H.-C. The current status of hydrogenstorage in metal-organic frameworks. Energy Environ. Sci. 2008, 1, 222-235. [CrossRef]

186. Li, Y.; Xie, L.; Liu, Y.; Yang, R.; Li, X. Favorable hydrogen storage properties of M(HBTC)(4,4'-bipy)·3DMF (M = Ni and Co). Inorg. Chem. 2008, 47, 10372-10377. [CrossRef] [PubMed]

187. Chun, H.; Jung, H.; Koo, G.; Jeong, H.; Kim, D.-K. Efficient hydrogen sorption in 8-connected MOFs based on trinuclear pinwheel motifs. Inorg. Chem. 2008, 47, 5355-5359. [CrossRef] [PubMed]

188. Wang, Z.; Tanabe, K.K.; Cohen, S.M. Tuning hydrogen sorption properties of metal-organic frameworks by postsynthetic covalent modification. Chem. Eur. J. 2010, 16, 212-217. [CrossRef] [PubMed]

189. Zhang, D.S.; Chang, Z.; Li, Y.F.; Jiang, Z.Y.; Xuan, Z.H.; Zhang, Y.H.; Li, J.R.; Chen, Q.; Hu, T.L.; Bu, X.H. Fluorous metal-organic frameworks with enhanced stability and high $\mathrm{H}_{2} / \mathrm{CO}_{2}$ storage capacities. Sci. Rep. 2013, 3, 3312. [CrossRef]

190. Rostami, S.; Pour, A.N.; Salimi, A.; Abolghasempour, A. Hydrogen adsorption in metal- organic frameworks (MOFs): Effects of adsorbent architecture. Int. J. Hydrogen Energy 2018, 43, 7072-7080. [CrossRef]

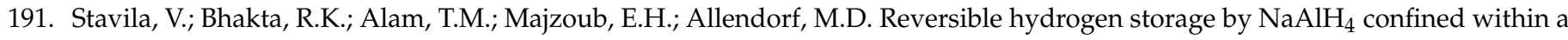
titanium-functionalized MOF-74(Mg) nanoreactor. ACS Nano 2012, 6, 9807-9817. [CrossRef]

192. Callini, E.; Szilágyi, P.Á.; Paskevicius, M.; Stadie, N.P.; Réhault, J.; Buckley, C.E.; Borgschulte, A.; Züttel, A. Stabilization of volatile $\mathrm{Ti}\left(\mathrm{BH}_{4}\right)_{3}$ by nano-confinement in a metal-organic framework. Chem. Sci. 2016, 7, 666-672. [CrossRef]

193. Hadjiivanov, K.I.; Panayotov, D.A.; Mihaylov, M.Y.; Ivanova, E.Z.; Chakarova, K.K.; Andonova, S.M.; Drenchev, N.L. Power of infrared and raman spectroscopies to characterize metal-organic frameworks and investigate their interaction with guest molecules. Chem. Rev. 2021, 121, 1286-1424. [CrossRef] [PubMed] 